\title{
Megacity emission plume characteristics in summer and winter investigated by mobile aerosol and trace gas measurements: the Paris metropolitan area
}

\author{
S.-L. von der Weiden-Reinmüller ${ }^{1}$, F. Drewnick ${ }^{1}$, Q. J. Zhang ${ }^{2,3}$, F. Freutel ${ }^{1}$, M. Beekmann ${ }^{2}$, and S. Borrmann ${ }^{1,4}$ \\ ${ }^{1}$ Particle Chemistry Department, Max Planck Institute for Chemistry, Mainz, Germany \\ ${ }^{2}$ Laboratoire Inter-universitaire des Systèmes Atmosphériques, UMR CNRS 7583, Université Paris Est Créteil et Université \\ Paris Diderot, Créteil, France \\ ${ }^{3}$ ARIA Technologies, Boulogne-Billancourt, France \\ ${ }^{4}$ Institute for Physics of the Atmosphere, Johannes Gutenberg University Mainz, Mainz, Germany
}

Correspondence to: F. Drewnick (frank.drewnick@mpic.de)

Received: 13 December 2013 - Published in Atmos. Chem. Phys. Discuss.: 7 May 2014

Revised: 16 September 2014 - Accepted: 17 September 2014 - Published: 8 December 2014

\begin{abstract}
For the investigation of megacity emission plume characteristics mobile aerosol and trace gas measurements were carried out in the greater Paris region in July 2009 and January-February 2010 within the EU FP7 MEGAPOLI project (Megacities: Emissions, urban, regional and Global Atmospheric POLlution and climate effects, and Integrated tools for assessment and mitigation). The deployed instruments measured physical and chemical properties of submicron aerosol particles, gas phase constituents of relevance for urban air pollution studies and meteorological parameters. The emission plume was identified based on fresh pollutant (e.g., particle-bound polycyclic aromatic hydrocarbons, black carbon, $\mathrm{CO}_{2}$ and $\mathrm{NO}_{\mathrm{x}}$ ) concentration changes in combination with wind direction data. The classification into megacity influenced and background air masses allowed a characterization of the emission plume during summer and winter environmental conditions. On average, a clear increase of fresh pollutant concentrations in plume compared to background air masses was found for both seasons. For example, an average increase of $190 \%\left(+8.8 \mathrm{ng} \mathrm{m}^{-3}\right)$ in summer and of $130 \%\left(+18.1 \mathrm{ng} \mathrm{m}^{-3}\right)$ in winter was found for particle-bound polycyclic aromatic hydrocarbons in plume air masses. The aerosol particle size distribution in plume air masses was influenced by nucleation and growth due to coagulation and condensation in summer, while in winter only the latter process (i.e., particle growth) seemed to be initiated by urban pollution. The observed distribution of fresh pollutants
\end{abstract}

in the emission plume - its cross sectional Gaussian-like profile and the exponential decrease of pollutant concentrations with increasing distance to the megacity - are in agreement with model results. Differences between model and measurements were found for plume center location, plume width and axial plume extent. In general, dilution was identified as the dominant process determining the axial variations within the Paris emission plume. For in-depth analysis of transformation processes occurring in the advected plume, simultaneous measurements at a suburban measurement site and a stationary site outside the metropolitan area using the mobile laboratory have proven to be most useful. Organic aerosol oxidation was observed in summer, while in winter transformation processes seemed to occur at a slower rate.

\section{Introduction}

The number of people living on this planet is steadily growing. In 2011 the 7 billion mark was exceeded (United Nations, 2013) and a continuous increase is projected for the next decades (Stiftung Weltbevölkerung, 2013). Since the 19th century the global phenomenon of urbanization can be observed. In 2008 more than $50 \%$ of the world population lived in urban agglomerations and this percentage is still increasing (United Nations, 2012). Worldwide the number of so-called megacities, defined by 10 million and more 
inhabitants (Molina and Molina, 2004), rose from 2 in 1970 to 23 in 2011 and is expected to reach a number of 37 in 2025 (United Nations, 2012). These intense hot spots of human activities come along with major challenges like urban planning, transportation, industrial development and urban pollution. Questions concerning the influence of urban areas on local, regional and global air quality with its impacts on human health, flora and fauna as well as atmospheric chemistry and climate are heavily discussed in the scientific community (e.g., Fenger, 1999; Akimoto, 2003; Crutzen, 2004; Molina and Molina, 2004; Gurjar and Lelieveld, 2005; Fenger, 2009; Parrish and Zhu, 2009; Kunkel et al., 2012).

The European Union FP7 MEGAPOLI project (Megacities: Emissions, urban, regional and Global Atmospheric POLlution and climate effects, and Integrated tools for assessment and mitigation; Baklanov et al., 2010) involved two intensive field campaigns in summer 2009 and winter 2010 in the mid-latitude European megacity of Paris, in order to characterize air pollution in and around such a large agglomeration and to investigate megacity emission evolution. The measurements at fixed ground-based sites and from research aircraft and mobile laboratories were complemented with satellite observations and local, regional and global modeling (Beekmann et al., 2014). State-of-the-art instrumentation, like ensemble and single particle aerosol mass spectrometers (Gard et al., 1997; Drewnick et al., 2005; DeCarlo et al., 2006; Brands et al., 2011) and proton-transfer-reaction mass spectrometers (de Gouw and Warneke, 2007), for the measurement of aerosol particle and trace gas loadings of the atmosphere were deployed for highly time-resolved analysis of the atmospheric composition.

Stationary measurements at different locations within the city (Crippa et al., 2013; Freutel et al., 2013) were mainly used to characterize the urban atmosphere in terms of source identification and impact of the city onto the air quality within the agglomeration. Contrary, here we focus on the characterization of the megacity emission plume downwind of the agglomeration and transformation processes within this plume during transport away from the source, including a discussion of meteorological influence observed during summer and winter conditions. For the investigation mobile and stationary measurement results from the mobile laboratory MoLa (Drewnick et al., 2012) were used, partially in combination with stationary measurements at a suburban measurement site (Freutel et al., 2013) and with modeling results (Zhang et al., 2013). Urban emission plumes have been investigated in the field so far mainly by highaltitude research aircraft measurements (e.g., Nunnermacker et al., 1998; Brock et al., 2003, 2008; Guttikunda et al., 2005; Bahreini et al., 2009), by deploying research vessels (e.g., de Gouw et al., 2008) and fixed measurement stations (e.g., Roldin et al., 2011; Slowik et al., 2011). The measurement data obtained by the mobile aerosol research laboratory MoLa provide new information about near-ground properties of a megacity emission plume and the large amount of data helps to quantify these properties. In the methodical part of this work the emphasis is on the retrieval of positive matrix factorization results from on-line mass spectrometric measurements of sub-micron aerosol chemical composition. In the following, the emission plume and background air mass pollutant concentrations are compared and typical characteristics of the plume are described. In addition, the spatial distribution of pollutants within the plume is investigated and transformation processes occurring in the emission plume are analyzed.

\section{Methodology: measurements and data analysis}

\subsection{MEGAPOLI project and field campaigns}

MEGAPOLI project: the European Union FP7 MEGAPOLI project (Baklanov et al., 2010; MEGAPOLI Data Base, 2013) combines theoretical and experimental approaches to investigate the influence of megacities on air quality as air pollution hot spots. The two major field campaigns are focused on the post-industrial mid-latitude megacity Paris, one of the largest metropolitan areas in Europe with a population of around 11 million inhabitants (United Nations, 2012). The dense urbanized area is concentrated on a limited almost circular space with about $40 \mathrm{~km}$ diameter and is surrounded by rural areas with very little local emissions. The terrain is flat and regional atmospheric conditions are mainly driven by synoptic scale weather patterns (Baklanov et al., 2010).

Field campaigns: the summer field campaign took place from 1 to 31 July 2009 and the winter measurements from 15 January to 15 February 2010. Several fixed measurement sites were distributed over the Paris metropolitan area measuring urban and suburban air pollution. Research aircraft and mobile ground-based measurements additionally covered the surrounding rural areas to investigate the advected emission plume as well as background air masses. An overview of results based on data from the fixed measurement sites can be found, e.g., in Dolgorouky et al. (2012), Healy et al. (2012), Michoud et al. (2012), Crippa et al. (2013), Freutel et al. (2013) and Beekmann et al. (2014). An introduction to the applied mobile groundbased measurements and the methods used for their exploitation is provided in von der Weiden-Reinmüller et al. (2014).

The fixed-site measurements were focused on the aerosol and trace gas characterization of urban air pollution in comparison to long-range transported background air pollution and on source apportionment of organic aerosol within the megacity. In contrast, the mobile measurements presented here were mainly applied to investigate the emission plume and to provide "real" background measurements.

In the next section the mobile laboratory MoLa is briefly introduced. The adopted measurement strategies are described in Sect. 2.3. During the MEGAPOLI field campaigns MoLa was based at a suburban measurement site northeast 
of Paris (see Fig. S1 in the Supplement) and carried out several intercomparison measurements for quality assurance at all major measurement sites. Results from these intercomparisons can be found in Freutel et al. (2013) and von der Weiden-Reinmüller et al. (2014).

\subsection{Mobile laboratory "MoLa"}

The Mobile Laboratory "MoLa" developed by the Max Planck Institute for Chemistry in Mainz consists of a regular Ford Transit delivery vehicle as the platform with a fully equipped mobile aerosol and trace gas laboratory. The aerosol inlet system was optimized and characterized for minimum particle losses and sampling artifacts using the software tool Particle Loss Calculator (von der Weiden et al., 2009). An extensive description of MoLa including technical features, inlet system characterization and instrumental equipment is presented in Drewnick et al. (2012).

Instrumentation: for the MEGAPOLI field campaigns MoLa was equipped with the instrumentation for the investigation of

1. aerosol particle chemical composition in the $\mathrm{PM}_{1}$ size range, in particular

- non-refractory species (sulfate, nitrate, ammonium, chloride, organics; excludes sea salt, black carbon, mineral dust and metals),

- black carbon

- total particle-bound polycyclic aromatic hydrocarbons (PAHs);

2. aerosol particle total number concentration and size distribution by

- electrical mobility $(5.6-560 \mathrm{~nm})$,

- aerodynamic sizing $(0.5-20 \mu \mathrm{m})$

- light scattering $(0.25-32 \mu \mathrm{m})$;

3. atmospheric trace gases, in particular

- $\mathrm{O}_{3}, \mathrm{SO}_{2}, \mathrm{NO}, \mathrm{NO}_{2}, \mathrm{CO}$ and $\mathrm{CO}_{2}$.

Additionally, meteorological parameters as well as the GPS vehicle position were logged and events in the surrounding were filmed using a webcam. Table 1 summarizes the instruments used for the measurements presented in this study. In von der Weiden-Reinmüller et al. (2014) a more detailed table can be found, listing the deployed measurement devices including details on the instrumentation, time resolution, detection limits and general properties.

\subsection{Measurement strategies}

Using MoLa, measurements can be carried out stationary or while driving.
Stationary measurements: stationary measurements were performed with MoLa on 15 occasions during summer and 10 times during winter. Each of these individual measurement periods lasted several hours. The chosen measurement locations (see Fig. S1) either were selected to be influenced by air masses that passed the Paris metropolitan area, thus allowing to collect fresh urban emissions (i.e., downwind of Paris), or by long-range transported background air masses (e.g., upwind of Paris). The first option gives insight into temporal variations of the Paris emission plume and the second one provides information on the levels and variability of the "real" background air pollution burden. In a few cases it was possible to take advantage of a distinct wind shift during the day, allowing direct comparison of background and emission plume air pollution from a single stationary measurement.

Mobile measurements: mobile measurements (for an overview map see Fig. S1) were performed both as cross sections through the emission plume (six in summer, 17 in winter) and as quasi-Lagrangian axial measurements inside the plume while it travels away from the city (three in summer and three in winter). Cross section measurements cover one or several segments around Paris with nearly constant distance to the border of the agglomeration. They usually start in air masses not influenced by Paris emissions, then cross the emission plume and end again in background air masses. With this strategy a quantification of the influence of Paris' emissions on local/regional air quality is possible and a detailed picture of spatial plume shape and homogeneity is provided. Quasi-Lagrangian axial measurements start at the border of the agglomeration and follow (ideally) the same air parcel while it travels axially away from Paris. This measurement strategy allows investigation of physical (e.g., particle formation and growth) and chemical (e.g., oxidation of particulate organic matter) transformation processes of the aerosol inside the urban plume. It is also a suitable method for studying dilution processes with increasing distance to Paris. Details of the various MoLa measurement approaches for the investigation of megacity emissions are discussed in von der Weiden-Reinmüller et al. (2014).

\subsection{Data preparation for analysis}

Data preparation for analysis of mobile measurements is complex because not only the standard procedures, such as removal of outliers, application of calibrations, averaging on a common time base and interpretation of intercomparison measurements, have to be performed, but also labor has to be put in the removal of local pollution contamination from the data sets (see Sect. 2.4.1) or assignment of measurement time to measurement location. Advanced analysis of highresolution mass spectra (Aiken et al., 2007) or of organic aerosol by the application of positive matrix factorization (Lanz et al., 2007; Ulbrich et al., 2009) are already extensive for data sets with moderate changes of particulate organic matter concentration and composition, as encountered 
Table 1. Summary of measurement devices - including measured variable and measurement principle - deployed in the mobile laboratory MoLa during the MEGAPOLI summer and winter field campaigns. A table with more information on each of the instruments operated within MoLa can be found in von der Weiden-Reinmüller et al. (2014).

\begin{tabular}{lll}
\hline Measured variable & Measurement device & Measurement principle \\
\hline Size-resolved aerosol chemical composition & HR-ToF-AMS & Mass spectrometry \\
Black carbon mass concentration & MAAP & Light absorption \\
PAH mass concentration & PAS & Photoionization of particle-bound PAHs \\
Particle number concentration & CPC & Condensational growth and detection by light scattering \\
Particle size distribution & FMPS & Electrical mobility \\
Particle size distribution & APS & Aerodynamic sizing \\
Particle size distribution & OPC & Light scattering intensity \\
$\mathrm{O}_{3}, \mathrm{SO}_{2}, \mathrm{CO}, \mathrm{NO}, \mathrm{NO}_{2}$ mixing ratio & Airpointer & UV photometry, UV fluorescence, IR absorption, \\
& & chemiluminescence \\
$\mathrm{CO}_{2}, \mathrm{H}_{2} \mathrm{O}$ mixing ratio & LI-840 & IR absorption \\
$\mathrm{Wind}_{\text {speed, wind direction, temperature, }}$ & Meteorological Station & Common methods \\
precipitation, pressure, relative humidity & & \\
Vehicle location and speed & GPS & N/A \\
Driver's view through windshield & Webcam & N/A \\
\hline
\end{tabular}

during stationary measurements. During mobile measurements much more rapid variations of the aerosol particle characteristics are observed, resulting in additional complexity in application of such analysis tools (see Sects. 2.4.2 and 2.4.3).

\subsubsection{Removal of local contamination}

Local pollution - from the point of view of a mobile measurement of the regional distribution of air constituents - can be generated nearly everywhere by, e.g., vehicles in the vicinity of the driving MoLa, lop fires, barbecue activities, smoking, households while heating and cooking, bituminization works or various industrial processes when driving by such facilities. Generally, the emission characteristics of the phenomena under investigation (here the Paris emission plume) are not sufficiently different from those of local emitters. Local emissions are frequently mixed into the plume air masses, such that an undisturbed measurement is not possible. If we want to quantify the influence of Paris on local air quality or to investigate transformation processes of Paris emissions, it is essential to remove such sporadic local contamination as completely as possible from the measured data before further analysis. Otherwise it is not possible to clearly distinguish between the Paris emission plume and local contamination contribution, and the characterization of the urban plume would be significantly biased.

Several methods for the removal of local pollution contamination were tested (Drewnick et al., 2012). Finally, a "video analysis method" was applied to the MEGAPOLI mobile data sets. Here the videos recorded by a webcam looking through the windshield during the mobile trips were analyzed to identify time periods with potential local contamination. These time periods were excluded from the mobile data sets. Further details about the applied removal procedure can be found in von der Weiden-Reinmüller et al. (2014). The analysis results presented in this paper are based exclusively on the "decontaminated" data sets.

\subsubsection{High-resolution mass spectra analysis}

One advanced analysis method applied in this work is the analysis of high-resolution mass spectra using "Peak Integration by Key Analysis" (PIKA; ToF-AMS Analysis Software Homepage, 2013). The algorithm implementing this method is generally applied for in-depth analysis of high-resolution time-of-flight aerosol mass spectrometer (HR-ToF-AMS) data. While the standard AMS data analysis yields unit-mass resolution information only, PIKA is used to obtain information on individual fragment ions from the high-resolution mass spectra. In combination with APES (Analytical Procedure for Elemental Separation; ToF-AMS Analysis Software Homepage, 2013) it is possible to quantify the overall contribution of different elements $(\mathrm{H}, \mathrm{C}, \mathrm{O}, \mathrm{N}, \mathrm{S})$ to the highresolution AMS signals, enabling elemental analysis with the HR-ToF-AMS.

Combining these tools the $\mathrm{O} / \mathrm{C}$ ratio of the organic aerosol was calculated for the MEGAPOLI data sets. Only the peaks up to $m / z 100$ were considered to ensure sufficient resolution for separation of individual peaks. Since $m / z$ larger than 100 contain only a negligible fraction of the total mass (typically $<1 \%$ of the total signal and about $5 \%$ of the organic signal during the MEGAPOLI MoLa summer and winter measurements), this is an acceptable limitation. The $\mathrm{O} / \mathrm{C}$ ratio is an important marker for the oxidation level and therewith the age of the particulate organic matter (Aiken et al., 2007, 2008). In this study we used low $\mathrm{O} / \mathrm{C}$ ratios as a marker for fresh pollution in the Paris emission plume opposed to aged pollution in background air masses characterized by high $\mathrm{O} / \mathrm{C}$ ratios. 


\subsubsection{Positive matrix factorization}

The organic aerosol typically accounts for a large fraction of the ambient sub-micron particulate matter (Andreae, 2009). It can consist of multiple organic components from various sources, altered by atmospheric transformation processes (Jimenez et al., 2009). To separate the total measured particulate organic matter into a certain number of sub-categories, which are associated with either different sources of organic aerosol and/or certain oxidation levels ( age), "Positive Matrix Factorization" (PMF) was applied on the unit mass resolution mass spectra of organic aerosol obtained from AMS measurements. PMF generates "factors" without any a priori information, and the sum of their time series should represent most of the variation of the organic aerosol observed during the measurement. The number of factors is not fixed; therefore, it is typically necessary to compare the PMF results to additional measurement data to find a reasonable PMF solution with a certain number of factors representing best the total organic aerosol. Details about the mathematical principle of PMF, the applied PMF evaluation tool as well as details of application to ambient aerosol data can be found in Paatero and Tapper (1994), Paatero (1997), Lanz et al. (2007), and Ulbrich et al. (2009).

Uncertainties of PMF factors: while PMF calculates the optimum solution for each set of input parameters, an uncertainty is introduced into the PMF solution by the fact that the user can select several of these parameters arbitrarily and for some of these selections no objective criterions are available. Here we calculate the uncertainties of the PMF factors from the solutions obtained when varying the parameters "seed" and "fpeak". The seed parameter defines the start value of the mathematical procedure. By altering this parameter the robustness and uniqueness of the solution can be explored. The fpeak value describes the rotational freedom of the solution. Usually, an fpeak value of 0 is chosen if no strong evidence against this selection can be found (Ulbrich et al., 2009). But all fpeak values around 0 are valid - as all seed values are valid - and so variation of these parameters provides information about the uncertainty range of the obtained solution. For calculation of the uncertainty of the factors' mass spectra and time series the seed value was varied between 0 and 50 in steps of 1 (with fpeak $=0$ ) and the fpeak value between -1.5 and 1.5 in steps of 0.1 (with seed $=0$ ). The resulting 51 (for seed variation) and 31 (for fpeak variation) PMF factor mass spectra and time series were used to estimate the uncertainty of each PMF factor by means of standard deviation and mean values (Freutel et al., 2013).

In general, the uncertainty due to the fpeak variation is larger ( 2 to $32 \%$ for the different factors) than that due to the seed variation $(<1$ to $7 \%$ ), regarding the 5 factor solution in summer and the 3 factor solution in winter (see below) for the MoLa MEGAPOLI data set. The 6 factor solution in winter (see below) shows higher uncertainties ( 8 to $52 \%$ for seed variation and 12 to $52 \%$ for fpeak variation). This is likely due to the larger sensitivity of the solution when separating one factor into two that have very similar properties (i.e., similar mass spectra) but significant differences in source origin (i.e., in their time series). These PMF uncertainties add to the usual uncertainty of about $30 \%$ of ambient AMS data (Canagaratna et al., 2007) when calculating absolute mass concentrations for the individual factors.

Single data points with very high concentrations force the PMF algorithm to overemphasize these single events. The PMF results will be dominated by these few data points and biased results will be generated. The resulting solutions are possibly not well suitable to describe the overall variation of the organic aerosol. Therefore, data points with intense peaks in the organic time series, independent of the cause of these peaks, were removed before PMF was applied. The criterion for a peak to be removed was arbitrarily chosen to be $50 \mu \mathrm{g} \mathrm{m}^{-3}$ of total organic aerosol concentration (occurring a few times during mobile measurements). This threshold has nothing to do with local contamination events at the first place. Local pollution contamination, as defined above, was not removed from the AMS data before PMF application but afterwards from the resulting factor time series (after the PMF calculations were finished).

The results of the investigation of PMF factor uncertainties can be summarized as follows: the relative uncertainties of the AMS mass concentrations are significantly lower than those of the absolute values and thus do not affect the significance of the results presented in this work.

MEGAPOLI summer data: the number of PMF factors for the MoLa MEGAPOLI summer data set was varied between 2 and 10, with the 3 to 6 factor solutions producing explainable results that were examined in detail. The 3 factor solution consists of one factor describing a more oxidized organic aerosol (oxygenated organic aerosol, OOA) and two factors that are both mainly a mixture of hydrocarbon-like organic aerosol (HOA) and cooking-related organic aerosol (COA). Both factors have a lower $\mathrm{m} / \mathrm{z} 44$ (mainly $\mathrm{CO}_{2}^{+}$) to total organics ratio (see Supplement Sect. S1, Fig. S2), which is an approximate measure for the oxidation stage and therewith the age of the organic aerosol (Aiken et al., 2008), than the OOA factor. When adding one factor (4 factor solution) the HOA and COA become more clearly separated from the other factors. The new fourth factor (semivolatile oxygenated organic aerosol, SV-OOA) is mainly a fresher (lower $m / z 44$ to total organics ratio) semi-volatile part split from the OOA, the latter one consequently becoming more aged (oxidized) compared to the 3 factor solution (now called low-volatile oxygenated organic aerosol, LV-OOA). The SV-OOA factor also contains signatures of biomass burning organic aerosol. This 4 factor solution was used for intercomparison purposes with the fixed measurement sites (Freutel et al., 2013). Adding another factor (5 factor solution) changes the former HOA, COA and SV-OOA (now called SV-OOA1) factors only slightly. The previous LV-OOA factor again splits into a more aged LV-OOA and 
another SV-OOA factor. From comparison to reference mass spectra (see Supplement Sect. S1) it seems that this new SV-OOA factor (called SV-OOA2) is influenced by biogenic emissions that formed secondary organic aerosol. By adding one more factor to achieve the 6 factor solution the LVOOA becomes even more oxidized, while the formerly HOA, COA, SV-OOA1 and SV-OOA2 factors change only slightly. The new sixth factor again is a split-off of fresher organic aerosol from the former LV-OOA factor. It cannot be attributed to a specific source or process and seems to be a mixture of organic aerosol with medium volatility. We decided that the 5 factor solution provides the best view on the organic aerosol during the MEGAPOLI summer campaign measured with MoLa. In summary, the factors of the 5 factor solution are

- HOA: fresh pollution marker, associated with traffic emissions;

- COA: fresh pollution marker, associated with cooking emissions;

- SVOOA1: medium-aged pollution marker, associated with a mixture of various sources including biomass burning;

- SVOOA2: medium-aged pollution marker, associated with a mixture of various sources including biogenic emitters of precursor gases for secondary organic aerosol;

- LV-OOA: aged pollution marker, associated with longrange transported pollution.

In the Supplement (Sect. S1) the factors of the 5 factor solution and their identification are described in more detail.

MEGAPOLI winter data: for the MEGAPOLI winter data set also the 2 to 10 factor solutions were calculated, while the 3 to 6 factor solutions were examined in detail. The 3 factor solution consists of one factor related to biomass burning (biomass burning-related organic aerosol, BBOA), another factor associated with hydrocarbon-like organic aerosol (HOA) and one corresponding to the medium oxidized and aged fraction of the organic aerosol (OOA). When increasing the number of factors by one (4 factor solution) the mass spectra of the BBOA, HOA and OOA factors do not change significantly, but the new fourth factor appears to be a meaningless splitting. It consists mainly of $m / z 28$ and 44, while $\mathrm{m} / z 44$ was split from the other three factors without any apparent physical reason. Due to this the 4 factor solution is not regarded as useful for further analysis. For the 5 factor solution, again BBOA, HOA and OOA do not change much and a new meaningful factor related with cooking emissions (COA) appears, but the fifth factor again seems to be noninterpretable. Therefore, the 5 factor solution is also not considered for further analysis. The 6 factor solution gives six interpretable and reasonable factors. Here, each of the factors of the 3 factor solution splits into two factors when looking at the 6 factor solution. The BBOA factor splits into a fresher and a more aged BBOA fraction (indicated by lower/higher $m / z 44$ to total organics ratio, see Supplement Sect. S2, Fig. S3), the HOA factor splits into HOA related to traffic and HOA associated with cooking activities (COA), and the OOA factor splits into a highly aged (LV-OOA) and a less aged fraction (SV-OOA). We decided that the 6 factor solution provides the best and most detailed view on the organic aerosol during the MEGAPOLI winter campaign. In summary, the factors of the 6 factor solutions are

- HOA: fresh pollution marker, associated with traffic emissions;

- COA: fresh pollution marker, associated with cooking emissions;

- BBOA1: medium-aged pollution marker, associated with aged biomass burning emissions;

- BBOA2: fresh pollution marker, associated with fresh biomass burning emissions;

- SV-OOA: medium-aged pollution marker, associated with emissions from various sources;

- LV-OOA: aged pollution marker, associated with longrange transported pollution.

In the Supplement (Sect. S2) the factors of the 6 and also the 3 factor solution and their identification are described in more detail.

\section{Characteristics of the emission plume}

\subsection{Emission plume identification}

The Paris emission plume is generated by emissions from manifold pollution sources in the Paris metropolitan area. These sources include - among many others - traffic, domestic heating, cooking activities, industrial processes and building works. Therefore, the emission plume is expected to have higher loadings of freshly emitted pollutants compared to background air masses that already experienced aging processes like oxidation for several hours to days and recently collected only small amounts of fresh pollution (e.g., from scattered villages or highways). Since the background pollution burden can vary strongly with time (e.g., depending on air mass origin or meteorological conditions), appropriate threshold values need to be chosen from measurements performed in the same region and at a close time to discern plume and background air masses. To fulfill this requirement the mobile measurement routes were chosen to cover a sufficiently large area so that both, Paris influenced and not influenced air masses were measured during the same trip. 
The identification of the emission plume was performed in several steps:

1. The expected direction of the emission plumes was determined from meteorological forecasts and Prev'Air pollution forecasts. Based on this information the measurement route was chosen (for details see von der Weiden-Reinmüller et al., 2014).

2. All data sets from all measured variables (validated, cleaned from local pollution influence) were searched for fingerprints from the emission plume in the region where approximately - according to pollution re-analysis maps (for details see von der WeidenReinmüller et al., 2014) and meteorological data - the plume was expected. This step was made without any preference for certain types of variables like concentrations of fresh pollution markers.

3. The emission plume was identified by the combination of meteorological data, pollution re-analysis maps and a simultaneous increase of concentration levels in several measurement parameters.

In this process it turned out, that the emission plume was mainly visible in the data sets of fresh pollution markers. Therefore, these data were finally used to determine the location of the plume and of the background without plume influence. Only after this determination average plume and background concentrations were calculated for all variables. So the definition of plume and background air masses is based on the combination of information.

In the following, the procedures applied to identify time periods of plume and background measurements in the data sets are exemplified for the different types of measurements performed.

Mobile measurements: in Fig. 1a concentrations of fresh pollution markers $\left(\mathrm{NO}_{\mathrm{x}}\right.$, black carbon, $\mathrm{HOA}$ and $\left.\mathrm{CO}_{2}\right)$ plotted versus the corresponding covered angle relative to the Paris center recorded during a cross section measurement in winter are shown. The time resolution of the presented data is $1 \mathrm{~min}$. Two different air masses can be identified in this data set: background air masses $(B)$ and emission plume influenced air masses $(P)$. The emission plume was expected in the southeastern direction of Paris, based on pollution reanalysis maps and meteorological data. The emission plume can additionally be identified in the data by the simultaneous increase of concentrations of fresh pollution markers (e.g., black carbon, $\mathrm{HOA}, \mathrm{CO}_{2}$ and $\mathrm{NO}_{\mathrm{x}}$ ) compared to the average value and variability of the background levels. In the presented cross section example clearly higher concentrations were found in the 115 to $150^{\circ}$ sector (between east to south direction) relative to Paris. For example, the average $\mathrm{NO}_{\mathrm{x}}$ concentration between 115 and $150^{\circ}$ is $83.2( \pm 27.7) \mathrm{ppbV}$, while the average background value in this measurement example is $37.1( \pm 16.8) \mathrm{ppbV}$. Due to its intense and broad structure this plume-related increase in the levels of fresh pollution markers can clearly be separated from scattered pollution (e.g., $\mathrm{NO}_{\mathrm{x}}$ peak concentration of $95.9 \mathrm{ppbV}$ around $160^{\circ}$ ) that remained in the data set after contamination removal by video analysis. Compared to the air masses identified as emission plume the background air masses show nearly no considerable trend (increase or decrease in pollutant concentration) and have on average clearly lower fresh pollutant concentrations.

In Fig. 1b measured levels of the same variables serving as fresh pollution markers like in panel a are plotted versus the associated distance to the Paris center, recorded during a quasi-Lagrangian axial measurement in summer. On this day the emission plume was expected in the northeastern direction of Paris where the measurement was performed. The high pollution concentrations near the city (up to about $50 \mathrm{~km}$ distance) are identified as the emission plume (marked by the dotted vertical line and $P$ ), while air masses further away from Paris show nearly constant background values $(B)$ with only occasional local pollution influence. Since in any cases the measurements started in the morning near Paris and the most distant point was reached in the afternoon we assume that the slower decrease observed for the $\mathrm{CO}_{2}$ concentration is - at least to a certain degree - an artifact due to typical diurnal variations of this trace gas.

Generally, an influence of diurnal variations on the measured pollutant levels especially during axial measurements cannot be excluded. The measured pollutant levels are also potentially influenced by missing the emission plume with increasing distance to the source (Paris). However, we performed axial measurements only on days where a stable wind direction was predicted to minimize the risk of leaving the emission plume.

Stationary measurements: stationary measurement locations were chosen a priori to either be influenced by Paris emissions or to allow the measurement of the atmospheric background without any plume influence. Here, the critical parameter for the plume identification is mainly the wind direction. MoLa recorded local wind direction and speed at about $7 \mathrm{~m}$ above ground level. However, local winds can differ in direction and strength from the regional wind patterns due to small scale and surface layer effects. Since advection of the emission plume is a regional phenomenon the measured wind data were used in combination with air pollution re-analysis maps showing regional wind patterns. When measuring constantly in emission plume or background air masses the variability of pollution concentration depends mainly on changes of the emission rate of the Paris metropolitan area (e.g., morning rush hour), meteorological parameters (e.g., rainfall events) and boundary layer effects (e.g., breakup of the boundary layer in the morning). In these cases, low/high values cannot be associated to background/plume conditions without ambiguity. However, during stationary measurements with occurring wind direction shifts the emission plume can also be identified on the basis 

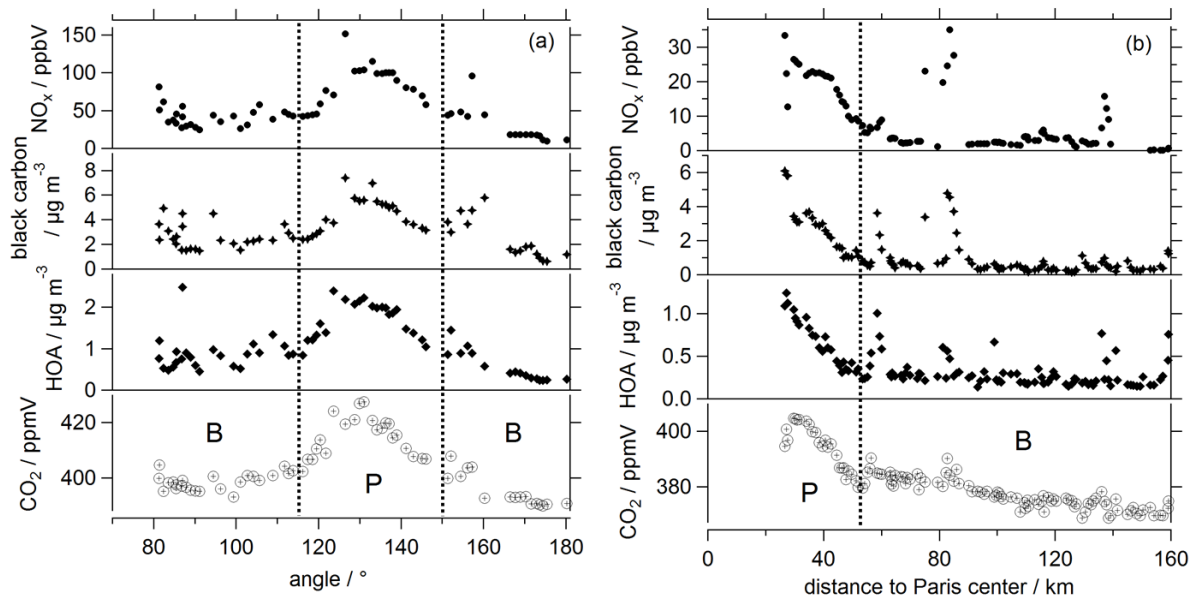

Figure 1. (a) Measured concentrations of fresh pollution markers $\left(\mathrm{NO}_{\mathrm{x}}-\right.$ dots, black carbon - stars, $\mathrm{HOA}-$ diamonds, $\mathrm{CO}_{2}-$ circles with crosses) versus covered angle related to the Paris center. The presented data were measured on 28 January 2010 during a cross section through the Paris emission plume, which was advected in southeastern direction during this day. The range between the two dashed vertical lines indicates plume air masses $(P)$. Background air masses are labelled with $B$. (b) Data of the same markers for fresh pollution as in (a) versus distance to the Paris center. These data were recorded during a quasi-Lagrangian axial measurement trip on 13 July 2009 . The Paris emission plume was advected in northeastern direction. The range left of the dashed vertical line indicates the emission plume $(P)$, while that to the right of it marks background air masses $(B)$. The time resolution of all data is $1 \mathrm{~min}$.

of enhanced fresh pollution concentrations like during cross section measurements.

Applying the described plume identification methods to all measurement data we classified them into emission plumeand background-related. In summer about 2800 and in winter about 3500 one-minute data points were classified as "background" $(B)$; in summer about 4100 and in winter about 3200 one-minute data points were classified as "emission plume" $(P)$. Data points not clearly fitting into one of the categories (e.g., time periods during stationary measurements with rapidly changing wind direction) were not considered in these statistics. Results of this emission plume versus background air mass characterization are presented in the following section. The MoLa measurements took place several tens of kilometers outside the city; consequently, the average pollution concentrations in the emission plume are representative for locations several tens of kilometers downwind of Paris.

\subsection{Emission plume versus background air mass characteristics}

It was found that meteorology and air mass origin have nearly the same influence on both categories $(B$ and $P$ ) during both measurement campaigns. For example, the average boundary layer height measured at the southwestern suburban measurement site (Beekmann et al., 2014) applying a LIDAR was during summer $(B: 1615( \pm 13) \mathrm{m}, P$ : $1616( \pm 9) \mathrm{m})$ and winter $(B: 465( \pm 4) \mathrm{m}, P: 414( \pm 5) \mathrm{m})$ approximately the same during the times when the emission plume and background air masses were probed. Therefore, the observed differences between emission plume and background characteristics are likely only marginally influenced by average associated meteorology or air mass origin differences. Average values of several measured variables for the two categories (background and emission plume) of the complete summer (S) and winter (W) campaign are presented in Figs. 2, 3 and 4. These values describe the average air quality around Paris in the distances (several tens of kilometers) where the measurements were carried out.

Pollutant concentrations: Fig. 2 provides a direct comparison for mean pollutant concentrations and their variation in background and plume air masses in summer and winter for the fresh pollution markers $\mathrm{CO}_{2}, \mathrm{NO}_{\mathrm{x}}, \mathrm{O}_{3}, \mathrm{SO}_{2}$, particle number concentration $(>2.5 \mathrm{~nm}), \mathrm{PM}_{1}$, black carbon, particle-bound PAH, chloride and HOA as well as the longrange transport pollution markers particulate sulfate, nitrate, ammonium and LV-OOA. Additionally, average $\mathrm{O} / \mathrm{C}$ ratios in organic aerosol are shown as indicator for air masses dominated by fresh pollution (low values) and aged pollution (high values). In Table 2 the contribution of the Paris emission plume to the concentration levels of the average background pollutant burden of the same parameters as shown in Fig. 2 are listed. The concentration values of the plume contribution were calculated as the difference of the average plume and background concentration levels.

Figure 2 and Table 2 clearly illustrate that emission plume air masses show higher fresh pollutant concentrations compared to background air masses during summer as well as during winter environmental conditions. For example, for black carbon concentrations an increase by $100 \%$ $\left(+0.5 \mu \mathrm{g} \mathrm{m}^{-3}\right)$ in summer and by $63 \%\left(+1.0 \mu \mathrm{g} \mathrm{m}^{-3}\right)$ in 

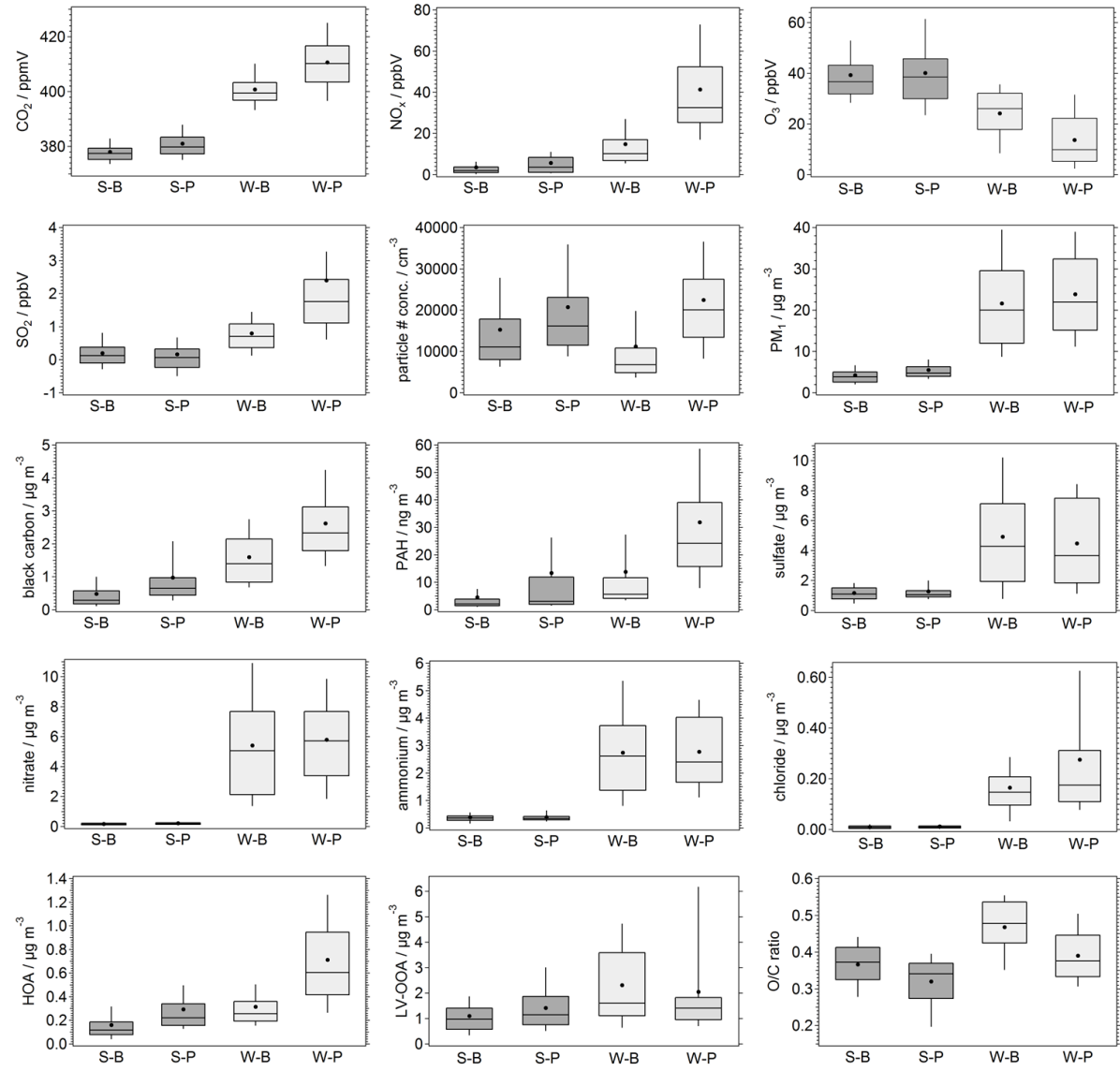

Figure 2. Mean values for background $(B)$ and emission plume $(P)$ air masses averaged for all measurements of the complete summer (S, dark grey filling) and winter (W, light grey filling) field campaigns for $\mathrm{CO}_{2}, \mathrm{NO}_{\mathrm{x}}, \mathrm{O}_{3}, \mathrm{SO}_{2}$, particle number concentration ( $>2.5 \mathrm{~nm}$ ), $\mathrm{PM} 1$ (calculated from AMS total plus black carbon mass concentration), black carbon, particle-bound PAH, sub-micron particulate sulfate, nitrate, ammonium, chloride, HOA, and LV-OOA mass concentrations and $\mathrm{O} / \mathrm{C}$ ratio. The data are presented as box-and-whisker plots with 10, 25, 50 (median), 75 and $90 \%$ percentiles. Additionally, the mean values are depicted as black dots.

winter was found when adding Paris emissions to the air masses. HOA mass concentrations were on average increased by $50 \%\left(+0.1 \mu \mathrm{g} \mathrm{m}^{-3}\right)$ in summer and $133 \%\left(+0.4 \mu \mathrm{g} \mathrm{m}^{-3}\right)$ in winter. The average $\mathrm{O} / \mathrm{C}$ ratios in organic aerosol confirm that during both seasons the oxidation level of the organic aerosol in emission plume air masses is significantly lower (much more than the uncertainty of the values) than that in background air masses. Additionally, one can see from the average $\mathrm{O} / \mathrm{C}$ ratios that during winter the organic aerosol is on average more oxidized than during summer, in plume as well as in background air masses. This could be explained by the fact that during summer more fresh organic particulate matter is generated (e.g., from biogenic emissions) by photochemical processes than in winter, favored by intense solar radiation. Additionally, the $\mathrm{O} / \mathrm{C}$ ratio of organic aerosol related to biomass burning is higher than the $\mathrm{O} / \mathrm{C}$ ratio of organic aerosol related to, e.g., traffic or cooking (see also Figs. S2 and S3). The biomass burning-related fraction of the total organic aerosol is much higher in winter than in summer (see Fig. 3).
$\mathrm{NO}_{\mathrm{x}}$ concentrations experienced an enhancement of $58 \%$ $(+2.1 \mathrm{ppbV})$ during summer and of $179 \%(+26.5 \mathrm{ppbV})$ in winter. The other measured fresh pollution markers showed a similarly clear enhancement in the emission plume. Only $\mathrm{SO}_{2}$ concentrations experienced on average no enhancement in plume air masses during summer. This can be explained by the spatial source distribution of $\mathrm{SO}_{2}$ emitters. Today, according to EU legislation fuel used in vehicles contains only a very small amount of sulfur (Fuel Quality Monitoring, 2013). The main $\mathrm{SO}_{2}$ emitters are in summer industrial activities and ship emissions on the open ocean (Corbett and Fischbeck, 1997; Diesch et al., 2013), so the $\mathrm{SO}_{2}$ sources are scattered over the country/sea instead of being concentrated in the city. In winter domestic heating leads to $200 \%$ $(+1.6 \mathrm{ppbV})$ higher $\mathrm{SO}_{2}$ concentrations in the plume than in background air masses (Fig. 2 and Table 2). The limit for the maximum sulfur content in fuel used for heating is higher than for that used for cars (see European Union council directives 93/12/EEC and 1999/32/EC; EUR-Lex, 2013). Since heating is in winter an important anthropogenic air pollution 
Table 2. Contribution of the Paris emission plume to $\mathrm{CO}_{2}, \mathrm{SO}_{2}, \mathrm{NO}_{\mathrm{x}}, \mathrm{O}_{3}$, particle number concentration $(>2.5 \mathrm{~nm})$, sub-micron black carbon, particle-bound $\mathrm{PAH}$, particulate ammonium, nitrate, sulfate, chloride, $\mathrm{PM}_{1}, \mathrm{HOA}$ and LV-OOA mass concentrations and $\mathrm{O} / \mathrm{C}$ ratio. The values were calculated as the difference of the plume and background concentration levels; the percentage change is related to the background concentrations, which are also listed including the respective standard deviation of the average values. The uncertainty of the plume contribution was calculated from the standard deviations of the average plume and background values. The $\mathrm{PM}_{1}$ mass concentration was calculated as the sum of the AMS total mass concentration (sum of organics, sulfate, nitrate, ammonium, and chloride) and the black carbon mass concentration.

\begin{tabular}{|c|c|c|c|c|c|c|}
\hline \multirow{2}{*}{$\begin{array}{l}\text { Measured } \\
\text { variable }\end{array}$} & \multicolumn{2}{|c|}{$\begin{array}{l}\text { Plume contribution } \\
\text { summer }\end{array}$} & \multicolumn{2}{|c|}{$\begin{array}{l}\text { Plume contribution } \\
\text { winter }\end{array}$} & \multirow{2}{*}{$\begin{array}{l}\text { Background } \\
\text { summer }\end{array}$} & \multirow{2}{*}{$\begin{array}{l}\text { Background } \\
\text { winter }\end{array}$} \\
\hline & absolute & relative & absolute & relative & & \\
\hline $\mathrm{SO}_{2}$ & $<0.1 \mathrm{ppbV}$ & & $+1.6 \pm 0.2 \mathrm{ppbV}$ & $+200 \%$ & $0.2 \pm 0.0 \mathrm{ppbV}$ & $0.8 \pm 0.0 \mathrm{ppbV}$ \\
\hline $\mathrm{NO}_{\mathrm{x}}$ & $+2.1 \pm 0.2 \mathrm{ppbV}$ & $+58 \%$ & $+26.5 \pm 0.6 \mathrm{ppbV}$ & $+179 \%$ & $3.6 \pm 0.2 \mathrm{ppbV}$ & $14.8 \pm 0.3 \mathrm{ppbV}$ \\
\hline $\mathrm{O}_{3}$ & $+0.8 \pm 0.3 \mathrm{ppbV}$ & $+2 \%$ & $-10.5 \pm 0.3 \mathrm{ppbV}$ & $-43 \%$ & $38.3 \pm 0.2 \mathrm{ppbV}$ & $25.1 \pm 0.2 \mathrm{ppbV}$ \\
\hline black carbon & $+0.5 \pm 0.0 \mu \mathrm{g} \mathrm{m}^{-3}$ & $+100 \%$ & $+1.0 \pm 0.0 \mu \mathrm{g} \mathrm{m}^{-3}$ & $+63 \%$ & $0.5 \pm 0.0 \mu \mathrm{g} \mathrm{m}^{-3}$ & $1.6 \pm 0.0 \mu \mathrm{g} \mathrm{m}^{-3}$ \\
\hline PAH & $+8.8 \pm 0.5 \mathrm{ng} \mathrm{m}^{-3}$ & $+191 \%$ & $+18.1 \pm 0.8 \mathrm{ng} \mathrm{m}^{-3}$ & $+131 \%$ & $4.6 \pm 0.2 \mathrm{ng} \mathrm{m}^{-3}$ & $13.8 \pm 0.5 \mathrm{ng} \mathrm{m}^{-3}$ \\
\hline ammonium & $<0.1 \mu \mathrm{g} \mathrm{m}^{-3}$ & & $<0.1 \mu \mathrm{g} \mathrm{m}^{-3}$ & & $0.4 \pm 0.0 \mu \mathrm{g} \mathrm{m}^{-3}$ & $2.7 \pm 0.0 \mu \mathrm{g} \mathrm{m}^{-3}$ \\
\hline nitrate & $+0.1 \pm 0.0 \mu \mathrm{g} \mathrm{m}^{-3}$ & $+50 \%$ & $+0.4 \pm 0.1 \mu \mathrm{g} \mathrm{m}^{-3}$ & $+7 \%$ & $0.2 \pm 0.0 \mu \mathrm{g} \mathrm{m}^{-3}$ & $5.4 \pm 0.1 \mu \mathrm{g} \mathrm{m}^{-3}$ \\
\hline LV-OOA & $+0.3 \pm 0.0 \mu \mathrm{g} \mathrm{m}^{-3}$ & $+27 \%$ & $-0.3 \pm 0.0 \mu \mathrm{g} \mathrm{m}^{-3}$ & $-13 \%$ & $1.1 \pm 0.0 \mu \mathrm{g} \mathrm{m}^{-3}$ & $2.3 \pm 0.0 \mu \mathrm{g} \mathrm{m}^{-3}$ \\
\hline $\mathrm{O} / \mathrm{C}$ ratio & $-0.05 \pm 0.00$ & $-14 \%$ & $-0.08 \pm 0.00$ & $-17 \%$ & $0.37 \pm 0.00$ & $0.47 \pm 0.00$ \\
\hline
\end{tabular}

source, the increased $\mathrm{SO}_{2}$ mixing ratios in emission plume as well as background air masses in winter compared to summer are explainable. The other fresh pollution components shown here are in both seasons mostly emitted by sources distributed all over the Paris region (e.g., $\mathrm{NO}_{\mathrm{x}}$ ). $\mathrm{O}_{3}$ mixing ratios were on average very similar in plume and background air masses in summer. Ozone depletion near the city due to increased NO mixing ratios and photochemical ozone production from urban precursor emissions seem to be balanced. In winter ozone production is reduced due to reduced solar radiation and biogenic volatile organic compound (VOC) emissions, so that on average $43 \%(-10.5 \mathrm{ppbV})$ lower $\mathrm{O}_{3}$ mixing ratios in plume compared to background air masses were observed.

In contrast to the fresh pollution markers those for aged pollution show nearly no or even opposite trends in concentration when comparing emission plume and atmospheric background values. For example, the observed difference for particulate sulfate between both categories $(B$ and $P$ ) is negligible in summer and small $(-8 \%)$ in winter. A similar finding of largest sulfate concentrations often occurring outside the pollution plume is also obtained from aircraft measurements with the ATR-42 aircraft during the summer campaign and was attributed to large harbor-related and ship emissions at the Channel coast (Freney et al., 2014). This difference is also negligible for ammonium in both seasons. For nitrate concentrations, an increased value in the plume is observed during the summer campaign, but absolute average values were small $\left(<0.3 \mu \mathrm{g} \mathrm{m}^{-3}\right)$. For the winter campaign the concentration in the plume is slightly increased $(+7 \%)$, but for much larger background values. The moderately increased $(+27 \%)$ average LV-OOA concentrations in the plume compared to background air masses in summer could be caused by organic aerosol with a medium oxidation level included in the calculated LV-OOA fraction. During summer oxidation rates can be very high (due to more intense solar radiation), so that some of the organic emissions and VOCs originating from Paris can already be converted to medium oxidized aerosol at the measurement location. However, these less aged organics seem to be on average a minor fraction of the LV-OOA. In winter oxidation rates are lower so that nearly no organic aerosol emitted in Paris ages to medium oxidized aerosol during these few hours of transport (see also Sect. 3.4).

The day to day variability of long-range transported pollution can of course be very high in Paris influenced as well as in uninfluenced air masses of varying origin. However, due to the large number of measurements being integrated in this statistical analysis, average concentrations of long-range transported pollutants are expected to be almost similar in both (plume and background) air mass types. In contrast to this, enhanced fresh pollutant concentrations in 
air masses advected from Paris compared to background air masses are predominantly caused by emitters located within the megacity. Thus, Paris has significant influence on the air quality in the surrounding regions. How far the spatial influence of the city reaches is discussed in Sect. 3.3.

Additionally, one can see in the presented data (Fig. 2, Table 2) that in general the atmospheric pollution burden is higher during winter than during summer. For example, particle-bound PAH mass concentrations were on average in background air masses during winter $\left(13.8 \mathrm{ng} \mathrm{m}^{-3}\right)$ three times higher than in background air masses during summer $\left(4.6 \mathrm{ng} \mathrm{m}^{-3}\right)$. Other pollution markers like black carbon and $\mathrm{NO}_{\mathrm{x}}$ also showed higher ambient background concentration (around 200\% higher for black carbon and around 300\% higher for $\mathrm{NO}_{\mathrm{x}}$ ) during winter, compared to the summer values. This is potentially caused by enhanced domestic heating but can also be influenced by reduced boundary layer heights in winter, where emissions are accumulated in a thinner atmospheric layer than during summer, and by slower removal processes (e.g., oxidation processes). The average boundary layer height measured at the southwestern suburban measurement site was during the summer campaign around $970( \pm 30) \mathrm{m}$ (average and standard deviation of the average) and during the winter campaign around $360( \pm 6) \mathrm{m}$, in agreement with the observed increased pollutant levels in winter. Additionally, comparatively more frequent continental advection (polluted air masses) occurred during the winter field campaign and more marine advection (clean air masses) during the one in summer (Beekmann et al., 2014). $\mathrm{CO}_{2}$ concentrations are additionally enhanced during winter season due to the reduced photosynthesis by plants. The fact that enhanced pollutant emission is not only a local issue can be seen by the much higher long-range transported pollution concentrations measured by MoLa during the winter campaign. For example, particulate sulfate concentrations were on average approximately $300 \%$ higher than in summer (in background air masses). For certain species this is not only caused by higher emission rates, but also gas-to-particle partitioning is an important factor. High vapor pressure species like ammonium nitrate partition predominantly into the gas phase during summer, but are found mainly in the particulate phase during winter. This explains the large difference between summer and winter concentrations in the plume as well as background air masses for these substances (e.g., 27 times higher concentrations of nitrate background concentrations in winter compared to summer, see Table 2).

Aerosol particle chemical composition: in Fig. 3 the average sub-micron aerosol particle chemical composition (including black carbon, organics, nitrate, sulfate, ammonium and chloride) and the average fractionation of the sub-micron organics (as retrieved by PMF analysis) is presented for both, the background and the plume aerosol in summer and winter. The presented concentration values of the composition of the Paris emission plume were calculated as the difference of the plume and background concentration levels. Negative values
Aerosol particle composition:
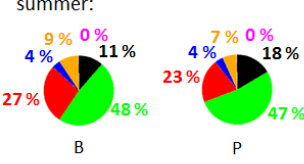

Fractionation of the particulate organic matter:

vinter:
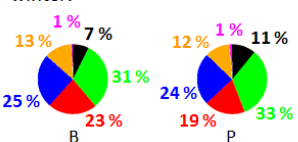

summer:

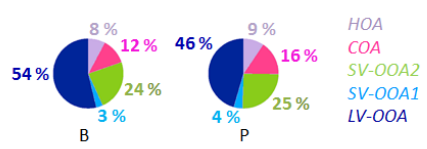

winter:
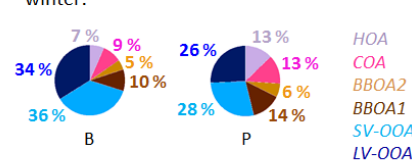

black carbon

organics

sulfe

itrate

chloride

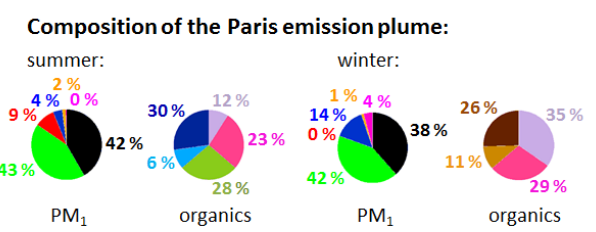

Figure 3. Mean sub-micron aerosol particle chemical composition for background $(B)$ and emission plume $(P)$ air masses averaged for all measurements of the complete summer and winter campaigns, consisting of black carbon (black), particulate organics (green), nitrate (blue), sulfate (red), ammonium (orange) and chloride (pink). Also shown is the average particulate organic matter fractionation during both campaigns. During summer the composition of the organic aerosol is best described by the 5 factor PMF solution: HOA (purple), COA (pink), SV-OOA2 (green), SV-OOA1 (light blue) and LV-OOA (dark blue). During winter the best description is the 6 factor solution: HOA (light purple), COA (pink), BBOA2 (light brown), BBOA1 (dark brown), SV-OOA (light blue) and LV-OOA (dark blue). The concentration values of the composition of the Paris emission plume were calculated as the difference of the plume and background concentration levels. Negative values (e.g., due to on average less sulfate concentrations in plume compared to background air masses in winter) are set to 0 for this calculation.

(e.g., due to on average lower sulfate concentrations in plume compared to background air masses in winter) are set to 0 in this calculation.

During summer average background $\mathrm{PM}_{1}$ mass concentrations were low with about $4.2 \mu \mathrm{g} \mathrm{m}^{-3}$ and the emission plume added about $31 \%$ - mainly black carbon and fresh organic matter (see Fig. 3) - to the background concentration (see Table 2). Thus, the aerosol in the emission plume contained a higher fraction of black carbon (18\%) than the aerosol in background air masses $(11 \%)$, causing the sulfate fraction (mostly long-range transported) to decrease from 27 to $23 \%$. Particulate organic matter consists of fresh and aged material. Its relative fraction of the total aerosol mass is nearly constant in both air masses, because the enhanced mass concentrations of fresh organics in the emission plume balance the enhanced black carbon concentrations in the plume. During summer ammonium and especially nitrate account only for a small part of the $\mathrm{PM}_{1}$ mass.

During winter average $\mathrm{PM}_{1}$ mass concentrations are five times higher than in summer and the emission plume adds on average about $10 \%$ to the background concentration (see 
Table 2). The averaged aerosol composition shows again a slightly increased fraction of black carbon $(+4 \%)$ and organic matter $(+2 \%)$ in the emission plume, but the differences between plume and background compositions are moderate. The larger fraction of nitrate in winter is explained by a shift in its partitioning between aerosol and gas phase (see above).

The calculated composition of the emission plume without the background contribution shows that in summer the additional organics in plume air masses are to one-third traffic(HOA, 12\%) and cooking-related (COA, 23\%). Biomass burning-related organics (e.g., from barbecue fires, lop fires) contribute to the emission plume with a fraction of $6 \%$ (SVOOA1, which has some biomass burning signatures). However, due to the moderate temperatures in summer, domestic heating is not a major source of organic aerosol, other than in winter. SV-OOA2 also contributes to the emission plume with about $28 \%$. Because this factor represents a mixture of medium-aged organic aerosol from various sources, including anthropogenic emitters over the greater Paris region, the observed enhancement in the emission plume is expected. Additionally, plume air masses were preferentially probed when the emission plume was transported to the northeast of Paris. Air masses coming from the southwestern direction crossed an extended forested area southwest of Paris (see Sect. 2.4.3 and von der Weiden-Reinmüller et al., 2014) before reaching the city and the measurement location. Therefore, biogenic secondary organic aerosol may also contribute to the plume air masses in summer. The LV-OOA fraction of the total $\mathrm{PM}_{1}$ mass decreases in plume air masses due to the increase of fresh particulate matter concentrations associated with urban emissions. The contribution of LV-OOA to the Paris emissions is about $30 \%$. This can be explained either by changes of long-range transported air mass origin (see also Fig. 2) and/or by rapid oxidation and aging of the organic aerosol and VOCs emitted in Paris (see also Sect. 3.4). The latter point would imply that the contribution of fresh organic aerosol sources to the total organic mass in the emission plume would be higher than assumed (see above).

During winter plume compared to background air masses also contained clearly more organic matter originating from traffic, cooking and biomass burning. Consequently, the medium-aged (SV-OOA) and strongly aged organic aerosol fraction (LV-OOA), which was not enhanced in the plume, decreases the most $(-8 \%$ for both). During winter fresh Paris emissions seem not to be oxidized to highly aged LVOOA as fast as in summer. In the emission plume approximately $46 \%$ of the organic aerosol is less oxidized, while in background air masses the fresh fraction only makes about $31 \%$. While in background air masses the sum of traffic- and cooking-related organics equals the biomass burning fraction, in plume air masses traffic and cooking are the more important sources. The additional organic matter in the emission plume $\left(+2.2 \mu \mathrm{g} \mathrm{m}^{-3}\right.$, see Table 2$)$ consists by twothirds of organics associated with traffic and cooking, while one-third is associated with biomass burning. This can be explained by strong traffic and cooking activities in Paris. Domestic heating will probably only partly be based on residential biomass burning (e.g., favoring district heating) in the city. In rural areas usually wood burning is a more common way of domestic heating.

Particle number size distributions: in Fig. 4 averaged particle number size distributions for emission plume and background air masses during summer and winter are presented. These data were measured by the FMPS (fast mobility particle sizer) instrument (size range 5.6 to $560 \mathrm{~nm}$ ). Again, the particle size distributions were calculated as average values for the two categories "background" $(B)$ and "emission plume" $(P)$ as described in Sect. 3.1., analog to the average pollution concentrations shown in Figs. 2 and 3. The contribution of the Paris emission plume (on top of the average background particle size distribution) is depicted as gray shaded area. In summer the background aerosol shows mainly one broad particle number distribution mode between a few $\mathrm{nm}$ and $200 \mathrm{~nm}$. This size distribution describes a mixture of small freshly emitted or recently nucleated particles and grown particles (due to condensation and accumulation processes) of different individual sizes. Paris emissions add on the one hand freshly produced particles that grow in size while the emission plume is transported away from the city. These particles form a distinct additional mode in the emission plume size distribution around $30 \mathrm{~nm}$. On the other hand also volatile organic components are emitted in the megacity, which become oxidized during emission plume advection. Under suitable environmental conditions these oxidation products can form new particles that likely cause the additional mode around $10 \mathrm{~nm}$ in the emission plume size distribution. Additionally, these substances can condense onto existing particles and increase their size. This is possibly one reason why the complete emission plume size distribution shows higher concentrations than the background distribution.

During winter the emission plume as well as the background size distribution show a distinct mode around $10 \mathrm{~nm}$ with similar particle number concentrations. This shows that new particle formation and emission of small particles seem to occur independently of megacity emissions in the area covered by the measurements. The large error bars especially of the background distribution indicate that there was a large temporal and spatial variation in the occurrence of small aerosol particles. In addition, the particle mode around $10 \mathrm{~nm}$ might be affected by artifacts due to the inversion algorithm used for this instrument (A. Wiedensohler, personal communication, 2012). Paris emissions only contribute to the accumulation mode between 20 and $200 \mathrm{~nm}$ in these measurements at some distance to the metropolitan area. Here the increase in number concentration is very strong. When comparing background and plume total particle number concentrations calculated from the FMPS data, in winter the megacity emissions caused on average an increase of 8000 

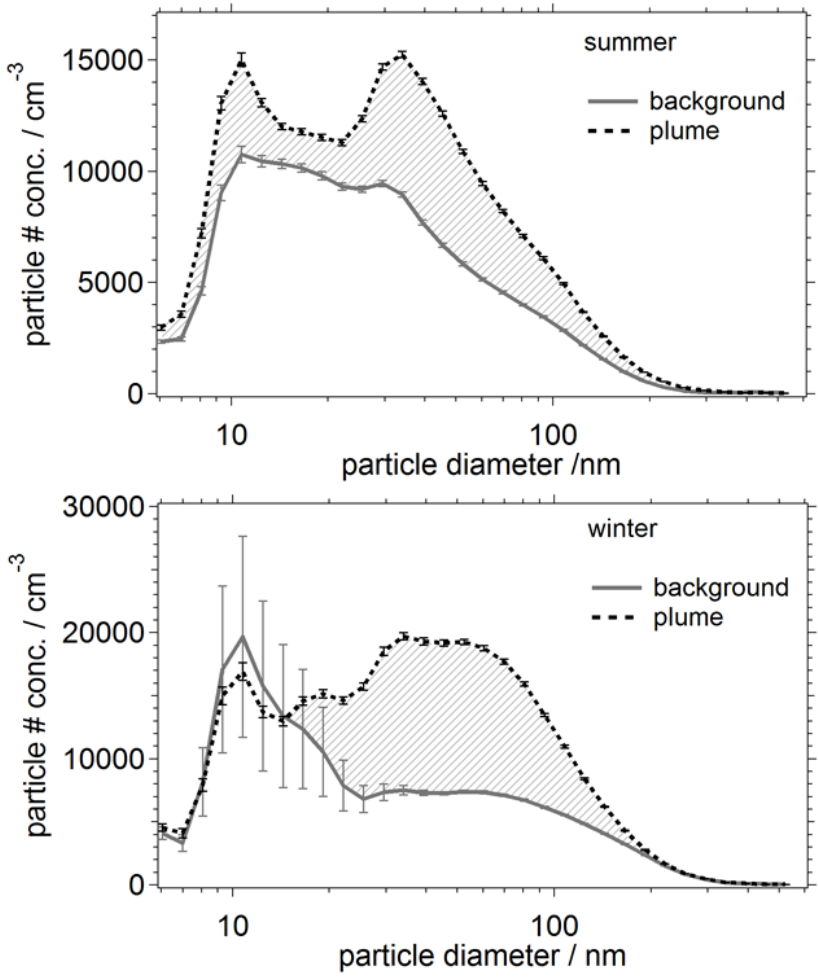

Figure 4. Averaged summer and winter particle number size distributions ( $\mathrm{dN}$ dlogDp ${ }^{-1}$ ) measured by the FMPS instrument. The solid gray line indicates the average size distribution of background air masses while the dotted black line represents the average particle distribution of the emission plume, respectively. The gray shaded area indicates the plume contribution as the resulting difference. The error bars represent the standard deviation of the average values.

particles per $\mathrm{cm}^{3}$ in plume air masses several ten kilometers away from the city. Consistently, the CPC data (number concentration for particles $>2.5 \mathrm{~nm}$ ) showed an average increase of 11300 particles per $\mathrm{cm}^{3}$ in plume compared to background air masses in winter (see Table 2). These particles were likely mainly emitted in the metropolitan area and grew rapidly into the accumulation mode due to low temperatures and high concentrations of condensable material. Increased emissions play a role, but also lower boundary layer heights when compared to summer.

In summary, it can be stated that the emission plume is in general characterized by clearly enhanced concentrations of fresh pollution markers. Traffic and cooking activities seem to be the major sources in summer, while in winter domestic heating additionally appears as a strong source. This fresh pollution adds to the transported background pollution. In summer the megacity emission plume is characterized by aerosol particles in the nucleation as well as accumulation mode size range, while in winter additional particles could only be observed in the accumulation mode. In general, air quality downwind of Paris seems to be better during summer, mainly because the background pollution is significantly lower compared to the winter.

\subsection{Homogeneity and spatial distribution of pollutants in the emission plume}

Cross section measurements give insight into dilution processes at the border of the plume and the plume width while axial trips allow an approximation of its spatial extent downwind of the source. Both measurement types also provide data to investigate how homogeneously the fresh emissions are mixed into the plume air masses. For this type of analysis the measured data were investigated in combination with simulations of the plume. These air quality simulations are based on the CHIMERE model and have a spatial resolution of $3 \mathrm{~km} \times 3 \mathrm{~km}$ (Zhang et al., 2013). For suitable measurement trips with distinct emission plumes modeled distributions of primary organic matter and $\mathrm{NO}_{\mathrm{x}}$ were temporally and spatially interpolated for the respective measurement route. Thus, two data sets could be compared: the actually measured time series of these two fresh pollution markers along the measurement track and the corresponding modeled time series showing where the emission plume was expected to be and how its shape was modeled.

Cross section: in Fig. 5a as an example measured and modeled $\mathrm{NO}_{\mathrm{x}}$ concentrations versus the covered angle in relation to the Paris center of a cross section measurement during the winter campaign are presented. Both measured and modeled data sets show a clear enhancement in pollutant concentrations when crossing the plume northwest of Paris. Gaussian fits to the data sets show good agreement and seem to be a suitable way to describe the plume's cross sectional distribution. This result is consistent with classical plume theory (Seinfeld and Pandis, 2006; Hunt and van den Bremer, 2011) and was also confirmed for Paris for ozone plumes on several occasions (Beekmann and Derognat, 2003). Apparently, turbulent dilution processes occur simultaneously and homogeneously at both sides of the plume, because the flat terrain around Paris favors uniform regional wind patterns. However, there are several significant differences between the measured and modeled emission plume. The apex of the Gaussian fit (and therewith the direction of the center of the emission plume) is shifted between the measured and modeled data $\left(+13^{\circ}\right.$ related to the measured plume peak in this example). In addition, the width of the modeled plume is approximately twice as large as the width of the measured one. When comparing the absolute $\mathrm{NO}_{\mathrm{x}}$ concentrations the measured concentrations are about three times larger than the modeled ones. These discrepancies can on the one hand be explained by different dilution rates and the purely regionalscale meteorology used in the model that does not include smaller scale processes. In the model, horizontal diffusion is not explicitly taken into account, but this is partly compensated by numerical diffusion in the advection scheme (Menut et al., 2013). In addition, plume dilution occurs by vertical 
mixing and a vertical wind shear. This process is taken into account, but the vertical model resolution is limited (six levels in the first two kilometers). On the other hand the actual $\mathrm{NO}_{\mathrm{x}}$ emissions within the city on this day could be much higher than those assumed in the model. Additionally, the distribution of emissions could lead to too large emissions in the surrounding areas (through a spatial redistribution of EMEP (European Monitoring and Evaluation Programme) emissions of $0.5^{\circ}$ resolution with respect to an urban land cover mask). However, systematic differences (widening, shifting, plume intensity) between measured and modeled emission plume depending on wind shift, wind speed and/or plume intensity were not observed when looking at all suitable cross section measurements.

For more measurement examples showing the cross sectional profile of the emission plume, and the corresponding model results, see Figs. S5, S6 and S7 in the Supplement Sect. S3.

Axial extent: Fig. 5b shows modeled primary organic matter and measured HOA (as approximation for primary organic matter) mass concentrations versus distance to the Paris center of one axial quasi-Lagrangian measurement during the summer campaign. Both data sets show decreasing pollutant concentrations with increasing distance to the metropolitan area. While the modeled concentrations continue decreasing over the whole distance range, the measured HOA values approach a constant background concentration of about 0.3 to $0.4 \mu \mathrm{g} \mathrm{m}^{-3}$ already much closer to the source. Both decreases can be well described with an exponential fit, while the decrease rate is clearly larger for the measured HOA concentrations. During the measurement trip the influence of the Paris emission plume was detected up to a distance of about $50 \mathrm{~km}$ from the center of Paris, while it can be seen in the modeled data up to at least $140 \mathrm{~km}$. This large discrepancy could be caused by too small effective horizontal dilution in the model (see above). The mixing of the emission plume with surrounding background air masses seems to take place very quickly. Also the apparently low background pollution concentrations in the modeled data bias the identification of the extent of the emission plume. Such low background concentrations are also the reason, why during aircraft measurements emission plumes can still be detected in much larger distances to the city. It could also be possible that the measurement route more and more deviated from the center of the plume with increasing distance to the city, so that decreasing pollution concentrations were also caused by varying positions of MoLa in relation to the plume center. The presented model data were interpolated to the driving route; however, as shown for the cross section measurement, a potential shifting of the location of the plume center between model and measurement cannot be excluded. Nevertheless, the analog exponential decrease in pollution concentrations with increasing distance to the source is in agreement with theoretical approaches applying turbulent diffusion processes (Seinfeld and Pandis, 2006).
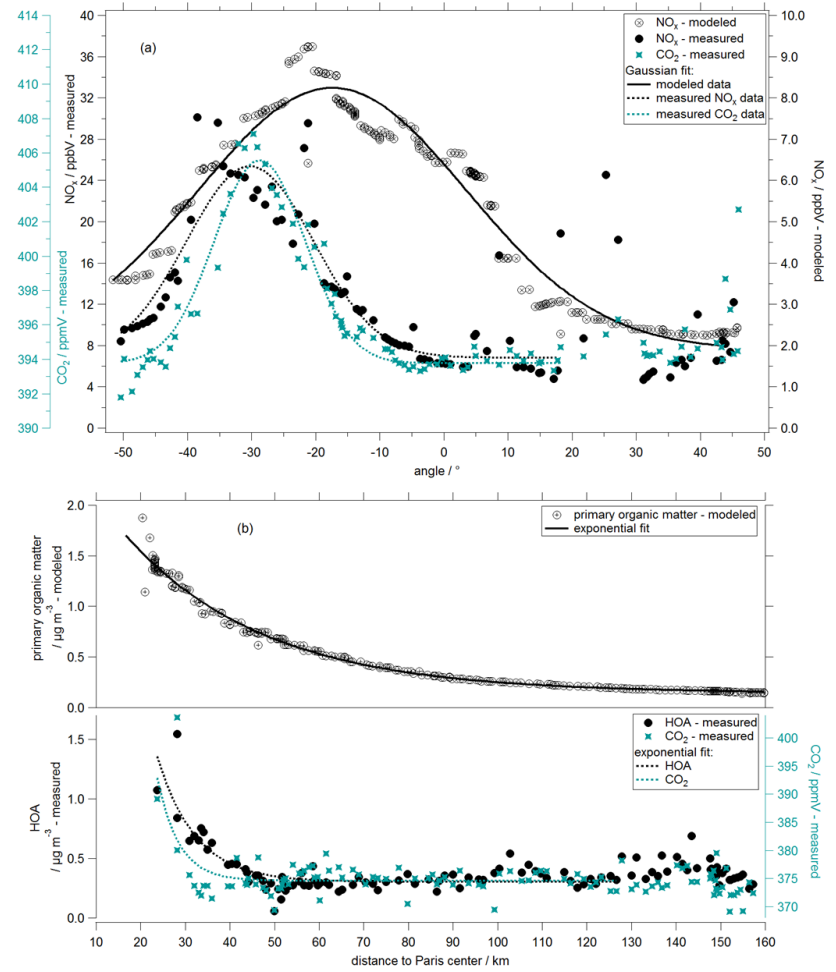

Figure 5. (a) Measured $\mathrm{NO}_{\mathrm{x}}$ (black dots, left axis) and $\mathrm{CO}_{2}$ (blue stars, left axis) and modeled $\mathrm{NO}_{\mathrm{x}}$ mixing ratios (black circles with crosses, right axis) versus the covered angle related to Paris of a cross section through the emission plume on 16 January 2010. The cross sectional route was in a distance of about $70 \mathrm{~km}$ from the city center. The respective Gaussian fits of the presented data are depicted as solid (for the modeled data) and dashed lines (measured data). (b) Measured HOA mass concentrations (black dots) and $\mathrm{CO}_{2}$ mixing ratios (blue stars) and modeled primary organic matter mass concentrations (black circles with crosses) versus distance to Paris center from a quasi-Lagrangian axial measurement on 1 July 2009. The respective exponential fits of the presented data are depicted as solid (modeled) and dashed lines (measured data). The time resolution of all data is $1 \mathrm{~min}$.

The presented structure of the plume can also be seen in other measured fresh pollution markers like $\mathrm{CO}_{2}$, which is also presented in Fig. 5a and b. There is a good agreement between the plume shape and spatial extent in the measured $\mathrm{NO}_{\mathrm{x}}, \mathrm{CO}_{2}$ and HOA concentrations. This gives further indication for a rather homogeneously mixed emission plume since sources of the different pollution markers are likely not all homogeneously distributed over the Paris area, but all fresh pollution markers show nearly the same homogeneous plume structure. Analysis of further measurements in addition to the two presented examples carried out during both field campaigns confirm the described results for the cross sectional and axial profile. However, deviations from the pure Gaussian plume shape (e.g., double peaks, asymmetric shapes) and alternating axial plume extensions were also observed, especially during more unstable weather conditions 
(e.g., changes of wind direction during the time of emission and measurement) and days with strong wind (favoring a fast axial transport of the plume). Corresponding measurement examples are shown in the Supplement Sect. S3. The differences between modeled and measured axial plume extent for the other axial trips are not that strong as in the presented example. For example, during the axial measurement trip on 13 July 2009 (outward trip) the axial plume extent is about up to $50 \mathrm{~km}$ from the city center in the modeled as well as in the measured data (see Fig. S8 in Sect. S3). During the winter campaign the axial trips were much shorter (up to $100 \mathrm{~km}$ ) than in summer (up to $180 \mathrm{~km}$ ) and the wind direction was not as stable as in summer. However, the database of 3 axial trips in summer and in winter is too small for a comprehensive comparison of model and measurement data.

For more measurement examples showing the exponential axial decrease of the emission plume, and the corresponding model results, see Figs. S8 and S9 in Sect. S3.

\subsection{Transformation processes in the emission plume}

Emitted substances originating from the megacity will not only be diluted in surrounding air masses while the plume is transported. Also transformation processes are expected to occur, especially when sufficient solar radiation favoring oxidation processes is present. For the investigation of transformation processes occurring in the advected emission plume, two different analysis approaches were applied.

Quasi-Lagrangian axial measurements: in the first approach the quasi-Lagrangian axial measurement (3 in summer and 3 in winter) results were used. Here the temporal transformation of pollutants (aging) should correlate with the distance to the Paris center. On average MoLa covered an axial distance of $30 \mathrm{~km}$ in about $1 \mathrm{~h}$ during the measurements, similar to the transport velocity of the plume. For the analysis of axial measurements it is assumed that $\mathrm{CO}_{2}$ is only diluted and does not experience any significant transformation processes during the first few hours of transport time in the emission plume. The excess (local concentration minus background concentration) of each variable compared to a suitable background value (values measured most far away from the city on the specific day) was calculated. The excess of each pollutant was related to the excess of $\mathrm{CO}_{2}$ to determine the result of aging processes for each substance by elimination of the influence of dilution.

Regarding all axial measurements during both field campaigns we can conclude that dilution is the dominant process occurring during emission plume transport within the first hours after emission. With this analysis method it was not possible to detect any significant chemical transformation process. Due to a number of reasons the data set is not robust enough to see significant trends besides dilution:

- The data variability within distance intervals (e.g., intervals from 30 to $40 \mathrm{~km}$ and from 40 to $50 \mathrm{~km}$ distance to Paris) and from trip to trip is high due to, e.g., remaining local pollution influence or changing meteorological conditions.

- An absolutely stable wind direction is indispensable for a successful axial trip inside the same air mass for several hours. If the wind direction is shifting during the measurement, the measurement track might not be located in the plume (center) during the complete measurement time. Misinterpretation of the data is possible, e.g., when a strong decrease in pollutant concentrations is interpreted as a strong dilution effect, but is in fact caused by leaving the plume (center).

- All axial trips started and ended nearly during the same time of day, so transformation processes are superimposed by diurnal variations.

- The number of axial trips is too small to provide a robust statistical basis for reliable conclusions.

Stationary measurements at two locations: in the second approach stationary measurements of MoLa were combined with continuous measurements during the same time at the fixed suburban measurement site in the northeast of Paris (Freutel et al., 2013). Due to similar instrumentation and intensive intercomparison exercises between the suburban northeastern measurement container and MoLa (Freutel et al., 2013, von der Weiden-Reinmüller et al., 2014) these data sets are well suited for combined analysis. Using this approach the plume can be studied and compared at two different ages: the fresh emission plume directly at the border of the spatially extended source and the emission plume after several hours of transport and aging time. Background pollutant contributions should be the same at both locations (under suitable conditions), so in theory differences result from the influence of Paris. The transport time was estimated from the distance between both measurement locations, the average wind speed measured at several stations and in several heights, calculated trajectories and comparison of changes in levels of long-range transported pollutants. While dilution processes will lead to decreasing concentrations with increasing distance from the source, transformation processes can change the observed concentrations or concentration ratios in both directions by consumption and production in chemical reactions or microphysical processes.

Here we focus on the analysis of conversion of particulate organic matter during transport, which is expected to experience significant changes as already discussed in Sect. 2.4.3. A necessary requirement for this analysis method is a connected flow between both measurement locations. We confirmed this situation by analysis of the measured wind direction at several stationary sites and additional backward trajectories utilizing HYSPLIT (Draxler and Rolph, 2013; Rolph, 2013) for one measurement day in summer and one in winter. The estimated transport time of the emission plume between the two locations ( $3 \mathrm{~h}$ for both measurements) was 
used to identify the corresponding time periods in both data sets that have to be compared for analysis. Average organic mass spectra were calculated for the two locations during the respective time periods, which comprise several hours of measurement time. Average organic mass spectra of the night before and the night after the actual measurement day, obtained during simultaneous measurements of MoLa at the suburban northeastern site, allow direct comparison of both applied AMS instruments. This comparison provides a factor that was applied to scale both organic mass spectra (actual measurement) to each other. This scaling factor accounts among others things - for slightly different ion transmission functions of the AMS instruments. For separation of dilution and transformation effects, an appropriate background organic mass spectrum was subtracted from the suburban and the MoLa average mass spectra. This background mass spectrum was calculated from MoLa background measurements at the same measurement location before and/or after probing the emission plume. In the next step the difference mass spectrum for the actual measurement was obtained by subtracting the suburban mass spectrum from the MoLa spectrum (both mass spectra were previously normalized to the total signal). The scaling of both mass spectra to the total signal also minimizes the influence of dilution effects during transport. The positive and the negative signals of this differential mass spectrum were separated into two single mass spectra. The mass spectrum resulting from the positive signals describes the fraction of the total organic aerosol that increases during transport while the other mass spectrum $(\mathrm{m} / \mathrm{z}$ with negative signals) describes the decreasing fraction (see Fig. S4). These two mass spectra were then compared to the MoLa PMF mass spectra derived for the respective field campaigns. The results of this comparison are presented in Table 3 . The described method has the advantage of comparing data of the same air mass measured almost simultaneously at two different locations. A second advantage is that MoLa's stationary measurement locations were always chosen to be not contaminated by any local pollution, which is not possible during mobile (axial) measurements (von der WeidenReinmüller et al., 2014).

As shown in Table 3 during summer the "decrease mass spectrum" correlates well with the fresh and medium-aged organic aerosol factors (HOA, COA, SV-OOA1 and SVOOA2: coefficient of determination $R^{2}=0.4$ to 0.5 , LVOOA: $R^{2}<0.1$ ), while the "increase mass spectrum" correlates only with LV-OOA $\left(R^{2}=0.8\right.$, other factors $\left.R^{2}<0.1\right)$. This means that besides of dilution effects, the fresher part of the organic aerosol decreases in concentration due to transformation processes as the air mass is transported from the city to the MoLa measurement location. The increase in LVOOA confirms the aging of less aged material during transport time. So there is indeed significant transformation (oxidation) of at least the organic aerosol occurring in the emission plume during summer (see also Sect. 3.2) within the first hours of plume transport. This result is in line with results
Table 3. Coefficients of determination $R^{2}$ from the comparison of the "increase mass spectrum" and the "decrease mass spectrum" with the PMF factor mass spectra of the 5 factor solution (summer) and the 6 factor solution (winter). For this comparison only the $m / z \leq 100$ were considered.

\begin{tabular}{lrr}
\hline$R^{2}$ & Increase & Decrease \\
\hline \multicolumn{3}{l}{ summer (27 July 2009): } \\
\hline HOA & $<0.1$ & 0.5 \\
COA & $<0.1$ & 0.4 \\
SV-OOA2 & $<0.1$ & 0.5 \\
SV-OOA1 & $<0.1$ & 0.5 \\
LV-OOA & 0.8 & $<0.1$ \\
\hline \multicolumn{2}{l}{ winter (27 January 2010): } \\
\hline HOA & 0.3 & $<0.1$ \\
COA & $<0.1$ & 0.2 \\
BBOA2 & 0.4 & $<0.1$ \\
BBOA1 & 0.1 & 0.3 \\
SV-OOA & 0.2 & $<0.1$ \\
LV-OOA & 0.1 & $<0.1$ \\
\hline
\end{tabular}

from aircraft measurements during the summer period, stating an increase of LV-OOA within the plume with increasing distance from Paris (Freney et al., 2014). In winter there is no clear similarity between the decrease and increase mass spectra and the PMF factors $\left(R^{2}\right.$ between 0 and 0.4 , but without clear trend). So the transformation of fresh pollution seems to take place at a slower speed than in summer. This goes in line with reduced oxidation rates during this season.

From these studies we can conclude that dilution is the dominating process determining the decrease in fresh pollution concentrations with increasing distance to the source. However, also transformation processes (oxidation of particulate organic matter) were detected. For a quantification of transformation processes applying the described method the available data basis is too small and not sufficiently robust. Further research utilizing several fixed and flexible stationary measurement locations under connected flow conditions is needed.

\section{Summary}

We present a detailed investigation of a mid-latitude European megacity emission plume based on mobile aerosol and gas phase measurements. The measurements were carried out in the framework of the MEGAPOLI project during two major field campaigns in summer 2009 and winter 2010 in the greater Paris region. The data obtained by the mobile laboratory MoLa were selectively combined with data measured at a fixed suburban site and model results to obtain extended information on plume properties and processes. Three mobile measurement strategies were applied depending on 
meteorological conditions. Quasi-Lagrangian axial measurements were used to explore the spatial extent of the emission plume, while cross section measurements allowed the investigation of plume shape and width and the direct comparison of plume and background conditions. Flexible stationary measurements in emission plume as well as background air masses complement the mobile data set.

In the advanced data preparation for analysis local pollution contamination was removed from the data set. Positive matrix factorization was applied to AMS organic mass spectra to obtain additional chemical information about the particulate organic aerosol by separation of the organic aerosol into fractions (factors) related to different oxidation levels (ages) and source origins. For the summer data set five different factors were used to describe the organic particulate matter: traffic- and cooking-related organic aerosol and three fractions representing organic aerosol of different ages and mixtures of sources. In winter six factors describe best the organic aerosol: hydrocarbon-like organic aerosol related to cooking and traffic activities, respectively, organic aerosol related to biomass burning with two different oxidation levels and two factors associated with more oxidized mixtures of organic aerosol.

Based on fresh pollution marker concentration changes and prevailing wind direction in combination with reanalysis pollutant maps (simulations with the chemistrytransport model) the emission plume was identified in the measurement data. This classification allowed a quantitative characterization of emission plume versus background air mass characteristics. During both seasons the emission plume was represented by a clear increase in fresh pollutant concentrations (e.g., increase in black carbon concentration of $100 \%\left(+0.5 \mu \mathrm{g} \mathrm{m}^{-3}\right)$ in summer and $63 \%\left(+1.0 \mu \mathrm{g} \mathrm{m}^{-3}\right)$ in winter). No similar increase was observed for concentrations of secondary pollutants such as particulate sulfate (in both seasons). In winter higher local and transported air pollution levels were measured than during summer due to increased emissions, less vertical dispersion, more continental conditions and enhanced partitioning into the aerosol phase (especially for particulate nitrate). The sub-micron aerosol particle composition was found to be influenced mainly by air mass origin and megacity contribution. The megacity mainly contributed fresh organic aerosol and black carbon to the aerosol. This additional organic particulate matter is related to cooking and traffic activities in summer, while in winter additionally biomass burning is an important source. While the measurements presented here confirm those at the fixed sites (Crippa et al., 2013; Freutel et al., 2013), they have the advantage of covering a larger measurement area with less permanent influence of local pollution (von der WeidenReinmüller et al., 2014). This is in particular the case for cooking-related organic aerosols which could be impacted by local activities especially at the urban measurement site.

Particle number size distributions in plume air masses show on the one hand additional freshly produced particles and on the other hand particle growth over a wide size range. Further analysis revealed that fresh pollution was rather homogeneously distributed in the emission plume. The cross sectional profile of the plume is typically Gaussian-like while the axial decrease of fresh pollution concentrations shows an exponential shape. On ground-level the emission plume could be detected up to $50 \mathrm{~km}$ from the city center. This value corresponds to a lower limit of the actual plume extension. The range of the detected emission plume was mainly determined by dilution processes. Exemplary model results confirmed the Gaussian profile but partially showed deviating center direction and width of the plume. Also dilution processes in the simulated plume seemed to occur much slower/weaker in the model than reflected in our measurements. However, a detailed model evaluation including more than a few "snapshots" is beyond the scope of this publication. The combination of MoLa stationary measurement data sets with results from a fixed suburban measurement location showed significant organic aerosol aging during summer. In winter this transformation seemed to occur more slowly due to the different environmental conditions.

Our analysis results add interesting new aspects about near-ground emission plume characteristics, extending the knowledge so far obtained by research aircraft, ship and stationary measurements as well as model studies. The large amount of valuable data obtained with the MoLa measurements allowed a quantification of properties of the Paris megacity emission plume.

\section{The Supplement related to this article is available online at doi:10.5194/acp-14-12931-2014-supplement.}

Acknowledgements. The MoLa team (Max Planck Institute for Chemistry, MPI-C) thanks T. Böttger, J.-M. Diesch, K. Dzepina, J. Fachinger, S. Gallavardin, T. Klimach, P. Reitz, A. Roth, J. Schmale, J. Schneider and S. R. Zorn for support during organization, preparation and realization of the measurement campaigns. The Golf Départemental de la Poudrerie (Livry-Gargan, Seine-Saint-Denise) is gratefully acknowledged for hosting the suburban northeastern stationary measurement and MoLa parking site. The contribution of Max Planck Institute for Chemistry's scientists to the MEGAPOLI campaigns and data analysis was fully covered by internal funds of the MPI-C Particle Chemistry Department.

The contribution of the groups from Laboratoire Interuniversitaire des Systèmes Atmosphériques and their campaign participation was supported by the European Union's Framework Program FP/2007-2011 within the project MEGAPOLI, grant agreement no. 212520

We extend our acknowledgment to the staff at the southwestern suburban measurement site (SIRTA) for providing meteorological data.

The service charges for this open access publication have been covered by the Max Planck Society.

Edited by: A. Baklanov 


\section{References}

Aiken, A. C., DeCarlo, P. F., and Jimenez, J. L.: Elemental Analysis of Organic Species with Electron Ionization HighResolution Mass Spectrometry, Anal. Chem., 79, 8350-8358, doi:10.1021/ac071150w, 2007.

Aiken, A. C., DeCarlo, P. F., Kroll, J. H., Huffman, J. A., Docherty, K. S., Ulbrich, I. M., Mohr, C., Kimmel, J. R., Sueper, D., Sun, Y., Zhang, Q., Trimborn, A., Northway, M., Ziemann, P. J., Canagaratna, M. R., Onasch, T. B., Alfarra, M. R., Prévôt, A. S. H., Dommen, J., Duplissy, J., Metzger, A., Baltensperger, U., and Jimenez, J. L.: O / C and OM / OC Ratios of Primary, Secondary, and Ambient Organic Aerosols with High-Resolution Time-ofFlight Aerosol Mass Spectrometry, Environ. Sci. Technol., 42, 4478-4485, doi:10.1021/es703009q, 2008.

Akimoto, H.: Global Air Quality and Pollution, Science, 302, 17161719, doi:10.1126/science.1092666, 2003.

Andreae, M. O.: A New Look at Aging Aerosols, Science, 326, 1493-1494, doi:10.1126/science.1183158, 2009.

Bahreini, R., Ervens, B., Middlebrook, A. M., Warneke, C., de Gouw, A. J., DeCarlo, P. F., Jimenez, J. L., Brock, C. A., Neuman, J. A., Ryerson, T. B., Stark, H., Atlas, E., Brioude, J., Fried, A., Holloway, J. S., Peischl, J., Richter, D., Walega, J., Weibring, P., Wollny, A. G., and Fehsenfeld, F. C.: Organic aerosol formation in urban and industrial plumes near Houston and Dallas, Texas, J. Geophys. Res., 114, D00F16, doi:10.1029/2008JD011493, 2009.

Baklanov, A., Lawrence, M., Pandis, S., Mahura, A., Finardi, S., Moussiopoulus, N., Beekmann, M., Laj, P., Gomes, L., Jaffrezo, J.-L., Borbon, A., Coll, I., Gros, V., Sciare, J., Kukkonen, J., Galmarini, S., Giorgi, F., Grimmond, S., Esau, I., Stohl, A., Denby, B., Wagner, T., Butler, T., Baltensperger, U., Builtjes, P., van den Hout, D., van der Gon, H. D., Collins, B., Schluenzen, H., Kulmala, M., Zilitinkevich, S., Sokhi, R., Friedrich, R., Theloke, J., Kummer, U., Jalkinen, L., Halenka, T., Wiedensohler, A., Pyle, J., and Rossow, W. B.: MEGAPOLI: concept of multiscale modelling of megacity impact on air quality and climate, Adv. Sci. Res., 4, 115-120, doi:10.5194/asr-4-115-2010, 2010.

Beekmann, M. and Derognat, C.: Monte Carlo uncertainty analysis of a regional-scale transport chemistry model constrained by measurements from the Atmospheric Pollution Over The Paris Area (ESQUIF) campaign, J. Geophys. Res., 108, 8559, doi:10.1029/2003JD003391, 2003.

Beekmann, M., Prévôt, A. S. H., Drewnick, F., Sciare, J., Pandis, S. N., van der Gon, H. A. C. D., Crippa, M., Freutel, F., Poulain, L., Ghersi, V., Rodriguez, E., Beirle, S., Zotter, P., von der WeidenReinmüller, S.-L., Bressi, M., Fountoukis, C., Petetin, H., Szidat, S., Schneider, J., Rosso, A., El Haddad, I., Megaritis, A., Zhang, Q., Slowik, J. G., Moukhtar, S., Kolmonen, P., Stohl, A., Eckhardt, S., Borbon, A., Gros, V., Marchand, N., Jaffrezo, J. L., Schwarzenboeck, A., Colomb, A., Wiedensohler, A., Borrmann, S., Lawrence, M., Baklanov, A., and Baltensperger, U.: Regional emissions control fine particulate matter levels in the Paris Megacity, Atmos. Chem. Phys. Discuss., in preparation, 2014.

Brands, M., Kamphus, M., Boettger, T., Schneider, J., Drewnick, F., Roth, A., Curtius, J., Voigt, C., Borbon, A., Beekmann, M. Bourdon, A., Perrin, T., and Borrmann, S.: Characterization of a Newly Developed Aircraft-Based Laser Ablation Aerosol Mass Spectrometer (ALABAMA) and First
Field Deployment in Urban Pollution Plumes over Paris During MEGAPOLI 2009, Aerosol Sci. Tech., 45, 46-64, doi:10.1080/02786826.2010.517813, 2011.

Brock, C. A., Trainer, M., Ryerson, T. B., Neuman, J. A., Parrish, D. D., Holloway, J. S., Nicks Jr., D. K., Frost, G. J., Hübler, G., Fehsenfeld, F. C., Wilson, J. C., Reeves, J. M., Lafleur, B. G., Hilbert, H., Atlas, E. L., Donnelly, S. G., Schauffler, S. M., Stroud, V. R., and Wiedinmyer, C.: Particle growth in urban and industrial plumes in Texas, J. Geophys. Res., 108, 4111, doi:10.1029/2002JD002746, 2003.

Brock, C. A., Sullivan, A. P., Peltier, R. E., Weber, R. J., Wollny, A., de Gouw, J. A., Middlebrook, A. M., Atlas, E. L., Stohl, A., Trainer, M. K., Cooper, O. R., Fehsenfeld, F. C., Frost, G. J., Holloway, J. S., Hübler, G., Neuman, J. A., Ryerson, T. B., Warneke, C., and Wilson, J. C.: Sources of particulate matter in the northeastern United States in summer: 2. Evolution of chemical and microphysical properties, J. Geophys., Res., 113, D08302, doi:10.1029/2007JD009241, 2008.

Canagaratna, M. R., Jayne, J. T., Jimenez, J. L., Allan, J. D., Alfarra, M. R., Zhang, Q., Onasch, T. B., Drewnick, F., Coe, H., Middelbrook, A., Delia, A., Williams, L. R., Trimborn, A. M., Northway, M. J., DeCarlo, P. F., Kolb, C. E., Davidovits, R., and Worsnop, D. R.: Chemical and microphysical characterization of ambient aerosols with the Aerodyne aerosol mass spectrometer, Mass Spectrom. Rev., 26, 185-222, 2007.

Corbett, J. J. and Fischbeck, P.: Emissions from Ships, Science, 278, 823-824, 1997.

Crippa, M., DeCarlo, P. F., Slowik, J. G., Mohr, C., Heringa, M. F., Chirico, R., Poulain, L., Freutel, F., Sciare, J., Cozic, J., Di Marco, C. F., Elsasser, M., Nicolas, J. B., Marchand, N., Abidi, E., Wiedensohler, A., Drewnick, F., Schneider, J., Borrmann, S., Nemitz, E., Zimmermann, R., Jaffrezo, J.-L., Prévôt, A. S. H., and Baltensperger, U.: Wintertime aerosol chemical composition and source apportionment of the organic fraction in the metropolitan area of Paris, Atmos. Chem. Phys., 13, 961-981, doi:10.5194/acp-13-961-2013, 2013.

Crutzen, P. J.: New Directions: The growing urban heat and pollution "island" effect - impact on chemistry and climate, Atmos. Environ., 38, 3539-3540, doi:10.1016/j.atmosenv.2004.03.032, 2004.

DeCarlo, P. F., Kimmel, J. R., Trimborn, A., Northway, M. J., Jayne, J. T., Aiken, A. C., Gonin, M., Fuhrer, K., Horvath, T., and Docherty, K. S:, Worsnop, D. R., and Jimenez, J. L.: Field-Deployable, High-Resolution, Time-ofFlight Aerosol Mass Spectrometer, Anal. Chem., 78, 8281-8289, doi:10.1021/ac061249n, 2006.

de Gouw, J. A. and Warneke, C.: Measurements of volatile organic compounds in the Earth's atmosphere using proton-transferreaction mass spectrometry, Mass Spec. Rev., 26, 223-257, 2007.

de Gouw, J. A., Brock, C. A., Atlas, E. L., Bates, T. S., Fehsenfeld, F. C., Goldan, P. D., Holloway, J. S., Kuster, W. C., Lerner, B. M., Matthew, B. M., Middlebrook, A. M., Onasch, T. B., Peltier, R. E., Quinn, P. K., Senff, C. J., Stohl, A., Sullivan, A. P., Trainer, M., Warneke, C., Weber, R. J., and Williams, E. J.: Sources of particulate matter in the northeastern Unites States in summer: 1. Direct emissions and secondary formation of organic matter in urban plumes, J. Geophys. Res., 113, D08301, doi:10.1029/2007JD009243, 2008. 
Diesch, J.-M., Drewnick, F., Klimach, T., and Bormann, S.: Investigation of gaseous and particulate emissions from various marine vessel types measured on the banks of the Elbe in Northern Germany, Atmos. Chem. Phys., 13, 3603-3618, doi:10.5194/acp-133603-2013, 2013.

Dolgorouky, C., Gros, V., Sarda-Esteve, R., Sinha, V., Williams, J., Marchand, N., Sauvage, S., Poulain, L., Sciare, J., and Bonsang, B.: Total $\mathrm{OH}$ reactivity measurements in Paris during the 2010 MEGAPOLI winter campaign, Atmos. Chem. Phys., 12, 95939612, doi:10.5194/acp-12-9593-2012, 2012.

Draxler, R. R. and Rolph, G. D.: HYSPLIT (HYbrid Single-Particle Lagrangian Integrated Trajectory) Model access via NOAA ARL READY Website, available at: http://ready.arl.noaa.gov/ HYSPLIT.php (last access: 11 December 2013), NOAA Air Resources Laboratory, Solver Spring, MD, 2013.

Drewnick, F., Hings, S. S., DeCarlo, P., Jayne, J. T., Gonin, M., Fuhrer, K., Weimer, S., Jimenez, J. L., Demerjian, K. L., Borrmann, S., and Worsnop, D. R.: A new Time-of-Flight Aerosol Mass Spectrometer (TOF-AMS) - Instrument Description and First Field Deployment, Aerosol Sci. Tech., 39, 637-658, doi:10.1080/02786820500182040, 2005.

Drewnick, F., Böttger, T., von der Weiden-Reinmüller, S.-L., Zorn, S. R., Klimach, T., Schneider, J., and Borrmann, S.: Design of a mobile aerosol research laboratory and data processing tools for effective stationary and mobile field measurements, Atmos. Meas. Tech., 5, 1443-1457, doi:10.5194/amt-5-1443-2012, 2012.

EUR-Lex: Access to European Union law, available at: http: //eur-lex.europa.eu/homepage.html (last access: 11 December 2013), 2013.

Fenger, J.: Urban air quality, Atmos. Environ., 33, 4877-4900, doi:10.1016/S1352-2310(99)00290-3, 1999.

Fenger, J.: Air pollution in the last 50 years From local to global, Atmos. Environ., 43, 13-22, doi:10.1016/j.atmosenv.2008.09.061, 2009.

Freney, E. J., Sellegri, K., Canonaco, F., Colomb, A., Borbon, A., Michoud, V., Doussin, J.-F., Crumeyrolle, S., Amarouch, N., Pichon, J.-M., Prévôt, A. S. H., Beekmann, M., and Schwarzenböeck, A.: Characterizing the impact of urban emissions on regional aerosol particles: airborne measurements during the MEGAPOLI experiment, Atmos. Chem. Phys., 14, 1397-1412, doi:10.5194/acp-14-1397-2014, 2014.

Freutel, F., Schneider, J., Drewnick, F., von der Weiden-Reinmüller, S.-L., Crippa, M., Prévôt, A. S. H., Baltensperger, U., Poulain, L., Wiedensohler, A., Sciare, J., Sarda-Estève, R., Burkhart, J. F., Eckhardt, S., Stohl, A., Gros, V., Colomb, A., Michoud, V., Doussin, J. F., Borbon, A., Haeffelin, M., Morille, Y., Beekmann, M., and Borrmann, S.: Aerosol particle measurements at three stationary sites in the megacity of Paris during summer 2009: Meteorology and air mass origin dominate aerosol particle composition and size distribution, Atmos. Chem. Phys., 13, 933-959, doi:10.5194/acp-13-933-2013, 2013.

Fuel Quality Monitoring: European Commission - Environment, available at: http://ec.europa.eu/environment/air/transport/fuel. htm (last access: 11 December 2013), 2013.

Gard, E., Mayer, J. E., Morrical, B. D., Dienes, T., Fergenson, D. P., and Prather, K. A.: Real-Time Analysis of Individual Atmospheric Aerosol Particles: Design and Perfor- mance of a Portable ATOFMS, Anal. Chem., 69, 4083-4091, doi:10.1021/ac970540n, 1997.

Gurjar, B. R. and Lelieveld, J.: New Directions: Megacities and global change, Atmos. Environ., 39, 391-393, doi:10.1016/j.atmosenv.2004.11.002, 2005.

Guttikunda, S. K., Tang, Y., Carmichael, G. R., Kurata, G., Pan, L., Streets, D. G., Woo, J.-H., Thongboonchoo, N., and Fried, A.: Impacts of Asian megacity emissions on regional air quality during spring 2001, J. Geophys. Res., 110, D20301, doi:10.1029/2004JD004921, 2005.

Healy, R. M., Sciare, J., Poulain, L., Kamili, K., Merkel, M., Müller, T., Wiedensohler, A., Eckhardt, S., Stohl, A. Sarda-Estève, R., McGillicuddy, E., O'Connor, I. P., Sodeau, J. R., and Wenger, J. C.: Sources and mixing state of size-resolved elemental carbon particles in a European megacity: Paris, Atmos. Chem. Phys., 12, 1681-1700, doi:10.5194/acp-12-1681-2012, 2012.

Hunt, G. R. and van den Bremer, T. S.: Classical plume theory: 1937-2010 and beyond, IMA J. Appl. Math., 76, 424-448, 2011.

Jimenez, J. L., Canagaratna, M. R., Donahue, N. M., Prévôt, A. S. H., Zhang, Q., Kroll, J. H., DeCarlo, P. F., Allan, J. D., Coe, H., Ng, N. L., Aiken, A. C., Docherty, K. S., Ulbrich I. M., Grieshop, A. P., Robinson, A. L., Duplissy, J., Smith, J. D., Wilson, K. R., Lanz, V. A., Hueglin, C., Sun, Y. L., Tian, J., Laaksonen, A., Raatikainen, T., Rautianinen, J., Vaattovaara, P., Ehn, M., Kulmala, M., Tomlinson, J. M., Collins, D. R., Cubison, M. J., Dunlea, E. J., Huffman, J. A., Onasch, T. B., Alfarra, M. R., Williams, P. I., Bower, K., Kondo, Y., Schneider, J., Drewnick, F., Borrmann, S., Weimer, S., Demerjian, K., Salcedo, D., Cottrell, L., Griffin, R., Takami, A., Miyoshi, T., Hatakeyama, S., Shimono, A., Sun, J. Y., Zhang, Y. M., Dzepina, K., Kimmel, J. R., Sueper, D., Jayne, J. T., Herndon, S. C., Trimborn, A. M., Williams, L. R., Wood, E. C., Middlebrook, A. M., Kolb, C. E., Baltensperger, U., and Worsnop, D. R.: Evolution of Organic Aerosol in the Atmosphere, Science, 326, 1525-1529, doi:10.1126/science.1180353, 2009.

Kunkel, D., Lawrence, M. G., Tost, H., Kerkweg, A., Jöckl, P., and Borrmann, S.: Urban emission hot spots as sources for remote aerosol deposition, Geophys. Res. Lett., 39, L01808, doi:10.1029/2011GL049634, 2012.

Lanz, V. A., Alfarra, M. R., Baltensperger, U., Buchmann, B., Hueglin, C., and Prévôt, A. S. H.: Source apportionment of submicron organic aerosols at an urban site by factor analytical modelling of aerosol mass spectra, Atmos. Chem. Phys., 7, 15031522, doi:10.5194/acp-7-1503-2007, 2007.

MEGAPOLI Data Base: MEGAPOLI Database - Paris, available at: http://ether.ipsl.jussieu.fr/megapoli/index.jsp (last access: 11 December 2013), 2013.

Menut, L., Bessagnet, B., Khvorostyanov, D., Beekmann, M., Blond, N., Colette, A., Coll, I., Curci, G., Foret, G., Hodzic, A., Mailler, S., Meleux, F., Monge, J.-L., Pison, I., Siour, G., Turquety, S., Valari, M., Vautard, R., and Vivanco, M. G.: CHIMERE 2013: a model for regional atmospheric composition modelling, Geosci. Model Dev., 6, 981-1028, doi:10.5194/gmd6-981-2013, 2013.

Michoud, V., Kukui, A., Camredon, M., Colomb, A., Borbon, A., Miet, K., Aumont, B., Beekmann, M., Durand-Jolibois, R., Perrier, S., Zapf, P., Siour, G., Ait-Helal, W., Locoge, N., Sauvage, S., Afif, C., Gros, V., Furger, M., Ancellet, G., and Doussin, J. F.: Radical budget analysis in a suburban European site during the 
MEGAPOLI summer field campaign, Atmos. Chem. Phys., 12, 11951-11974, doi:10.5194/acp-12-11951-2012, 2012.

Molina, M. J. and Molina, L. T.: Megacities and Atmospheric Pollution, J. Air Waste Ma., 54, 644-680, 2004.

Nunnermacker, L. J., Imre, D., Daum, P. H., Kleinman, L., Lee, Y.N., Lee, J. H., Springston, S. R., Newman, L., Weinstein-Lloyd, J., Luke, W. T., Banta, R., Alvarez, R., Senff, C., Sillman, S., Holdren, M., Keigley, G. W., and Zhou, X.: Characterization of the Nashville urban plume on July 3 and July 18, 1995, J. Geophys. Res., 103, 28129-28148, doi:10.1029/98JD01961, 1998.

Paatero, P.: Least square formulation of robust non-negative factor analysis, Chemometr. Intell. Lab., 37, 23-35, 1997.

Paatero, P. and Tapper, U.: Positive matrix factorization: a nonnegative factor model with optimal utilization of error estimated of data values, Environmetrics, 5, 111-126, 1994.

Parrish, D. D. and Zhu, T.: Clean Air for Megacities, Science, 326, 674-675, doi:10.1126/science.1176064, 2009.

Roldin, P., Swietlicki, E., Massling, A., Kristensson, A., Löndahl, J., Eriksson, A., Pagels, J., and Gustafsson, S.: Aerosol ageing in an urban plume - implication for climate, Atmos. Chem. Phys., 11, 5897-5915, doi:10.5194/acp-11-5897-2011, 2011.

Rolph, G. D.: Real-time Environmental Applications and Display sYstem (READY) Website, available at: http://ready.arl.noaa.gov (last access: 11 December 2013), NOAA Air Resources Laboratory, Silver Spring, MD, 2013.

Seinfeld, J. H. and Pandis, S. N.: Atmospheric Chemistry and Physics: From Air Pollution to Climate Change, John Wiley and Sons, 2nd Edn., New Jersey, 2006.

Slowik, J. G., Brook, J., Chang, R. Y.-W., Evans, G. J., Hayden, K., Jeong, C.-H., Li, S.-M., Liggio, J., Liu, P. S. K., McGuire, M., Mihele, C., Sjostedt, S., Vlasenko, A., and Abbatt, J. P. D.: Photochemical processing of organic aerosol at nearby continental sites: contrast between urban plumes and regional aerosol, Atmos. Chem. Phys., 11, 2991-3006, doi:10.5194/acp-11-29912011, 2011.

Stiftung Weltbevölkerung: Stiftung Weltbevölkerung, available at: http://weltbevoelkerung.de (last access: 11 December 2013), 2013.
ToF-AMS Analysis Software Homepage: ToF-AMS Analysis Software, available at: http://cires.colorado.edu/jimenez-group/wiki/ index.php/ToF-AMS_Analysis_Software (last access: 11 December 2013), 2013.

Ulbrich, I. M., Canagaratna, M. R., Zhang, Q., Worsnop, D. R., and Jimenez, J. L.: Interpretation of organics components from Positive Matrix Factorization of aerosol mass spectrometer data, Atmos. Chem. Phys., 9, 2891-2918, doi:10.5194/acp-9-2891-2009, 2009.

United Nations: World Urbanization Prospects: The 2011 Revision, available at: http://esa.un.org/unpd/wup/index.htm (last access: 11 December 2013), New York, 2012.

United Nations: World Populations Prospects: The 2012 Revision, available at: http://esa.un.org/unpd/wpp/index.htm (last access: 11 December 2013), New York, 2013.

von der Weiden, S.-L., Drewnick, F., and Borrmann, S.: Particle Loss Calculator - a new software tool for the assessment of the performance of aerosol inlet systems, Atmos. Meas. Tech., 2, 479-494, doi:10.5194/amt-2-479-2009, 2009.

von der Weiden-Reinmüller, S.-L., Drewnick, F., Crippa, M., Prévôt, A. S. H., Meleux, F., Baltensperger, U., Beekmann, M., and Borrmann, S.: Application of mobile aerosol and trace gas measurements for the investigation of megacity air pollution emissions: the Paris metropolitan area, Atmos. Meas. Tech., 7, 279-299, doi:10.5194/amt-7-279-2014, 2014.

Zhang, Q. J., Beekmann, M., Drewnick, F., Freutel, F., Schneider, J., Crippa, M., Prévôt, A. S. H., Baltensperger, U., Poulain, L., Wiedensohler, A., Sciare, J., Gros, V., Borbon, A., Colomb, A., Michoud, V., Doussin, J.-F., Denier van der Gon, H. A. C., Haeffelin, M., Dupont, J.-C., Siour, G., Petetin, H., Bessagnet, B., Pandis, S. N., Hodzic, A., Sanchez, O., Honoré, C., and Perrussel, O.: Formation of organic aerosol in the Paris region during the MEGAPOLI summer campaign: evaluation of the volatilitybasis-set approach within the CHIMERE model, Atmos. Chem. Phys., 13, 5767-5790, doi:10.5194/acp-13-5767-2013, 2013. 